\title{
Update on heart failure management and future directions
}

\author{
Hong-Mi Choi ${ }^{1, \star}$, Myung-Soo Park ${ }^{2, \star}$, and Jong-Chan Youn ${ }^{2}$
}

\begin{abstract}
${ }^{1}$ Division of Cardiology, Hallym University Sacred Heart Hospital, Anyang; ${ }^{2}$ Division of Cardiology, Hallym University Dongtan Sacred Heart Hospital, Hwaseong, Korea
\end{abstract}

Received: November 28, 2018 Accepted: December 9, 2018

\section{Correspondence to}

Jong-Chan Youn, M.D.

Division of Cardiology, Hallym University Dongtan Sacred Heart Hospital, 7 Keunjaebong-gil, Hwaseong 18450, Korea

Tel: $+82-31-8086-2530$

Fax: +82-31-8086-2559

E-mail: jong.chan.youn@gmail.com

*These authors contributed

equally to this work.

This paper was contributed by The Korean Society of Cardiology.
Heart failure (HF) is an important cardiovascular disease because of its increasing prevalence, significant morbidity, high mortality, and rapidly expanding health care cost. The number of HF patients is increasing worldwide, and Korea is no exception. There have been marked advances in definition, diagnostic modalities, and treatment of HF over the past four decades. There is continuing effort to improve risk stratification of HF using biomarkers, imaging and genetic testing. Newly developed medications and devices for HF have been widely adopted in clinical practice. Furthermore, definitive treatment for end-stage heart failure including left ventricular assist device and heart transplantation are rapidly evolving as well. This review summarizes the current state-of-the-art management for HF and the emerging diagnostic and therapeutic modalities to improve the outcome of HF patients.

Keywords: Heart failure; Diagnosis; Management; Prognosis

\section{INTRODUCTION}

Heart failure (HF) is an important cardiovascular disease due to its increasing prevalence and high mortality rate. HF is associated with a diverse range of complications, such as hospitalization, lethal arrhythmia, and death during the disease progression. In addition, HF can be the terminal condition of many cardiovascular diseases, including myocardial infarction (MI), valvular heart disease, and various cardiomyopathies. Due to these unique characteristics, various pharmacological and non-pharmacological treatments have been developed, not only to improve underlying cardiac disease but also to prevent hospitalization and death. In this review, we will address the state-of-the-art management of $\mathrm{HF}$ and ongoing studies.

\section{DEFINITION, EPIDEMIOLOGY, AND DIAGNOSIS}

\section{Definition}

HF is a clinical syndrome characterized by distinct symptoms and signs, which is caused by structural and/ or functional cardiac abnormalities [1-3]. Currently, the most common terminology for describing HF is based on left ventricular ejection fraction (LVEF). HF with normal LVEF ( $\geq 50 \%$ ) is defined as HF with preserved ejection fraction (HFpEF), and HF with decreased LVEF $(<40 \%)$ as $\mathrm{HF}$ with reduced ejection fraction (HFrEF). HF patients with LVEF in the range of $40 \%$ to $49 \%$ are defined as HF with mid-range ejection fraction (HFmrEF). Although HFmrEF is now categorized as a separate entity, the epidemiology, pathophysiology, 


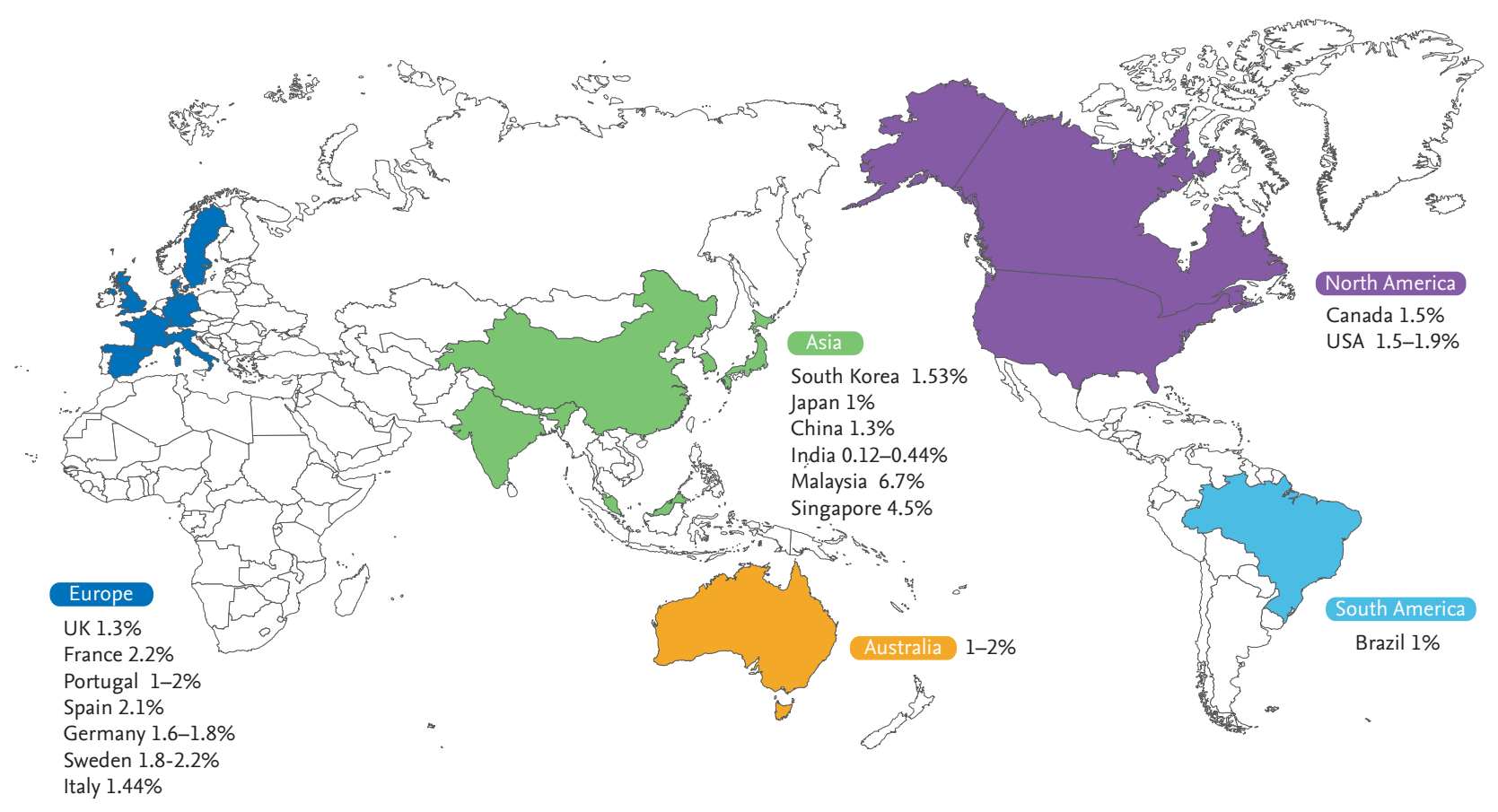

Figure 1. Global epidemiology of heart failure.

treatment, and prognosis of HFmrEF remain unclear [1].

The increasing amount of research in this area has gradually led to elucidation of the characteristics of HFmrEF, although there is still a great deal of debate. HFmrEF is a heterogeneous group comprised of at least three subsets: HFmrEF improved group (prior LVEF < 40\%), HFmrEF unchanged group (prior LVEF $40 \%$ to $49 \%$ ), and HFmrEF deteriorated group (prior LVEF $\geq 50 \%$ ). The improved and deteriorated groups account for $90 \%$ of the total, with the unchanged group accounting for only $10 \%$ of cases. Therefore, most patients classified as HFmrEF have various features of HFrEF and HFpEF, rather than belonging to groups with unique characteristics. These results indicate the limitations of the current HF classification system based on LVEF and, therefore, a novel taxonomy is required [4].

Several terms are often used to describe the status of HF patients. Patients with low LVEF and no symptoms or signs of HF can be described as having asymptomatic left ventricular (LV) systolic dysfunction. Patients experiencing HF symptoms and signs are described as having chronic HF, and those whose disease status does not change for at least 1 month are diagnosed as having stable HF. Patients with chronic stable HF showing unexpected deterioration are described as having decompensated HF. The New York Heart Association (NYHA) functional classification has been used to describe the severity of HF symptoms, and the Killip classification is used to describe the disease severity in patients after acute MI.

\section{Epidemiology}

The prevalence of HF differs according to definition and region, but has been estimated to be approximately $1 \%$ to $2 \%$ in developed countries (Fig. 1). The prevalence rate tends to increase with age, and it is $>10 \%$ among people $>70$ years old [5]. The epidemiological and etiological profiles of HFrEF and HFpEF are different. In comparison with HFrEF, patients with HFpEF are older, show female predominance, and often show hypertension and atrial fibrillation $(\mathrm{AF})$ with a lower rate of MI [6].

In Korea, the prevalence of HF in 2013 was $1.53 \%$ according to the National Health Insurance Service-National Sample Cohort [7]. The increasing prevalence of HF with age in Korea is consistent with the worldwide trend, and the rate was reported to be $1.0 \%$ for individ- 


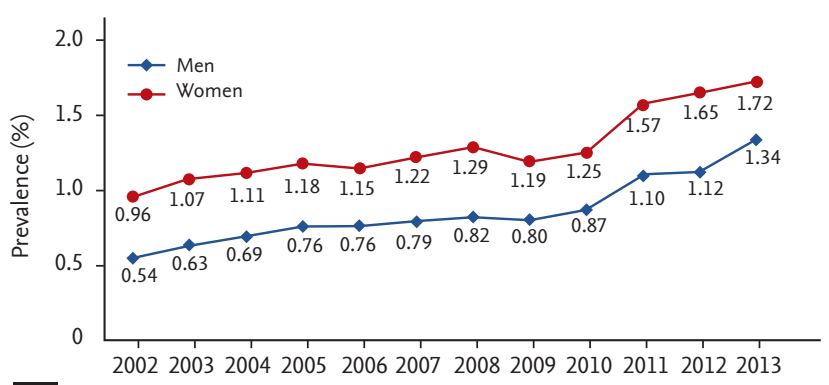

A Year

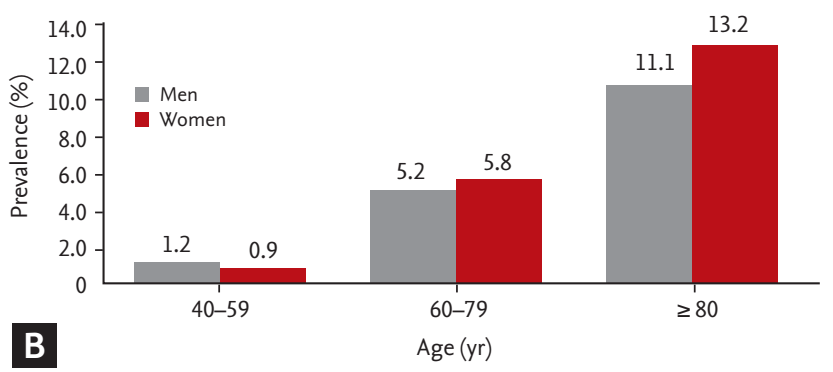

Figure 2. Epidemiology of heart failure in Korea according to (A) years and (B) age and sex. Adapted from Lee et al. [7].

uals below 60 years old, $5.5 \%$ for those aged 60 years or older, and $12.6 \%$ for those aged 80 years or older (Fig. 2) [7].

\section{Diagnosis}

In the initial evaluation of $\mathrm{HF}$, it is necessary to examine natriuretic peptides (NPs) and to perform echocardiography [1]. Both B-type natriuretic peptide (BNP) and N-terminal pro-BNP (NT-proBNP) have diagnostic power and are applicable to HFrEF and HFpEF. In situations when echocardiography is not immediately available, examination of NPs allows identification of patients requiring further cardiac evaluation by determining the likelihood of HF. In patients with NP values below the cut-off, HF can be excluded because the negative predictive value of NPs is very high (0.94 to 0.98). On the other hand, the positive predictive value is relatively low (0.66 to 0.67 ), so the use of NPs is suitable for excluding HF, but not for confirming the diagnosis [8].

Echocardiography is the most useful test providing immediate information, including systolic and diastolic function of LV and right ventricle (RV), chamber size, wall thickness, and valve abnormalities. Physicians can establish the precise diagnosis of HF and set up a treatment plan based on echocardiographic findings.

\section{STRATEGIES TO PREVENT NEW-ONSET HEART FAILURE IN PATIENTS WITH RISK FACTORS}

There is considerable evidence on how to prevent the development of overt HF. Hypertension is one of the major risk factors of HF. Many studies have indicated that proper control of blood pressure can prevent HF. In the Systolic Blood Pressure Intervention Trial (SPRINT), intensive blood pressure control (systolic blood pressure $<120 \mathrm{mmHg}$ ) was more beneficial for the prevention of cardiovascular diseases than standard treatment, but controversy over optimal blood pressure persists because the study population had a high risk of cardiovascular disease [9]. With regard to diabetes mellitus, recent studies have shown that sodium-glucose cotransporter-2 (SGLT-2) inhibitors reduced mortality and HF hospitalization in type 2 diabetic patients. In patients with ST-segment elevation MI, rapid primary percutaneous coronary intervention and administration of angiotensin-converting enzyme inhibitor (ACEI), $\beta$-blocker, mineralocorticoid receptor antagonist (MRA), and statin can reduce HF hospitalization and mortality. In addition, ACEI and $\beta$-blocker can decrease mortality in patients with coronary artery disease (CAD) without LV systolic dysfunction and reduce HF hospitalization in patients with asymptomatic LV systolic dysfunction, regardless of the etiology [1].

\section{EMERGING CARDIAC IMAGING AND OTHER DIAGNOSTIC TESTS}

Cardiac imaging enables us to visualize and quantify the structure and function of the heart. LVEF is not only the most widely used indicator of systolic function but is also one of the most powerful prognostic markers in patients with HF. As LVEF is crucial for diagnosis, classification, and establishment of an appropriate management plan, transthoracic echocardiography is the most important tool in the initial evaluation of HF patients. Recently, strain measured by echocardiography and other modalities such as cardiovascular magnetic resonance (CMR) and computed tomography (CT) have attracted attention. In this section, we review emerging imaging modalities in the field of HF. 


\section{Strain imaging}

Left ventricular strain

LVEF can divide the HF population into two groups according to prognosis and drug responsiveness: HFrEF vs. $\mathrm{HFpEF}$. In HF patients with $\mathrm{LVEF} \geq 45 \%$, mortality does not show a negative correlation with $\operatorname{LVEF}[10,11]$. Moreover, most drugs used for HF show a mortality benefit only in patients with HFrEF, and not in those with HFmrEF and HFpEF [12]. This is because LVEF cannot discriminate subclinical LV dysfunction from normal systolic function. In addition, substantial numbers of patients with cardiomyopathy other than ischemic cardiomyopathy have preserved systolic function. Therefore, there is a need for a more accurate prognostic marker to classify HF patients, and LV global longitudinal strain (GLS) is expected to be useful in this regard [13,14]. Park et al. [14] demonstrated the utility of LV-GLS as a prognostic indicator in patients with acute HF throughout all ranges of LVEF. They demonstrated that the rate of all-cause death was well stratified according to GLS, but not to LVEF [14]. With regard to the specific etiology of HF, LV-GLS worse than $-14 \%$ was an independent predictor of all-cause mortality and hospitalization for HF in acute MI with LVEF > 40\% [15]. In patients receiving potentially cardiotoxic chemotherapy, baseline and follow-up measurement of LV-GLS are recommended because LV-GLS can detect early subclinical LV dysfunction in these patients [16].

\section{Right ventricular strain}

The RV has a complex structure that causes difficulty in the estimation of systolic function. The pathophysiology of RV dysfunction is also complex, because RV function is influenced by a wide range of factors, such as volume status, pulmonary vascular resistance, and LV function [17]. Therefore, many studies have failed to show the predictive value of RV function in patients with HF [18]. RV strain has recently become one of the most actively investigated topics in the measurement of RV function [19]. Iacoviello et al. [20] reported that RVGLS and RV free wall strain were independent predictors of all-cause mortality in patients with chronic stable HF. The most recent study, including 1,824 patients with acute HF, showed that the group with decreased biventricular strain had the poorest prognosis. In addi- tion, poorer RV-GLS was an independent predictor of all-cause mortality in acute HF patients without pulmonary hypertension [21]. Limitations, such as intervendor variability, the impact of age and sex, load dependency, and variable cutoff value, make GLS difficult to incorporate into daily practice; however, accumulating evidence may result in more universal usage of GLS in the future $[13,16,22]$.

\section{$\mathrm{CT}$ and $\mathrm{CMR}$}

Cardiac CT can be used to evaluate the coronary arteries in HF patients with low to intermediate pretest probability of CAD or equivocal noninvasive stress test results. CMR has the unique advantage of myocardial tissue characterization, which helps to determine the etiology of various cardiomyopathies and estimate myocardial viability. However, the role of imaging modalities other than transthoracic echocardiography was restricted in the 2016 European Society of Cardiology (ESC) guidelines to estimation of the etiology in HF patients [1].

With recent progress in CMR techniques, additional information about myocardial tissue has become available. Pre- and post-contrast Ti time and extracellular volume (ECV) are known to be related to myocardial tissue composition [23]. Mascherbauer et al. [24] reported a negative correlation between post-contrast $\mathrm{T} 1$ time and $\mathrm{E} / \mathrm{e}^{\prime}$ in $61 \mathrm{HFpEF}$ patients with diagnoses confirmed by right heart catheterization. They also showed that short post-contrast $\mathrm{T} 1$ time $(<388.3 \mathrm{~ms})$ was an independent predictor of HF hospitalization and cardiovascular mortality [24]. In a prospective cohort study of 117 non-ischemic dilated cardiomyopathy (NIDCM) patients, ECV was a better prognostic marker of cardiac events than the presence of mid-wall late gadolinium enhancement (LGE) [25]. However, the difference in administration, distribution, and excretion of gadolinium can cause potential variability of post-contrast T1 time and ECV and, therefore, native T1 has emerged as a new alternative method [26]. In 637 NIDCM patients, native T1 was an independent predictor of all-cause and HF composite endpoint, while post-contrast $\mathrm{T} 1$ was not [27].

Furthermore, efforts are being made to use CT for tissue characterization. Prior studies have shown that CT could be used to evaluate myocardial delayed enhancement for non-ischemic cardiomyopathy as well 
as MI, through similar contrast kinetics of iodine to gadolinium. Moreover, the recently developed dual-energy technique could improve the image quality of CT for evaluation of myocardial delayed enhancement through monochromatic imaging. Mapping of iodine distribution within the myocardium using the dual-energy technique could improve diagnostic accuracy for evaluation of myocardial perfusion and ECV fraction [28-30]. In patients with HF, myocardial scarring detected by CT is similar to the presence of LGE by CMR [31]. Despite limitations including radiation exposure and a shortage of experience, CT may supersede CMR in the future due to its versatility, especially in the field of ischemic cardiomyopathy [32].

\section{Novel biomarkers and genetic testing}

\section{Biomarkers}

As there is a considerable body of evidence for NP biomarkers, they have already been incorporated into the American expert consensus for HF [33]. In the European guidelines, NPs are essential elements for the diagnosis of HFpEF and acute HF [1].

There are increasing numbers of novel biomarkers. The biomarkers for myocardial injury and fibrosis, such as soluble suppression of tumorigenicity-2 (ST2), galectin-3, and high-sensitivity cardiac troponin, can be used for additive risk stratification in HF patients [33, 34]. Soluble ST2, a marker for cardiac stress and fibrosis, showed good performance for additive risk stratification of death in acute HF in an individual patient-based meta-analysis [35]. In addition, a smaller decrease in soluble ST2 48 hours after presentation was an independent predictor of 1-year mortality in patients with acute HF who visited the emergency department [36]. The value of soluble ST2 as a prognostic indicator was also demonstrated in ambulatory HF patients [37]. Notably, soluble ST2 can be useful in patients with renal insufficiency because it is not influenced by renal function [37, 38]. Galectin-3 is a marker of inflammation and fibrosis. It can also provide prognostic information in patients with acute or chronic HF and identify patients who can benefit from medical therapy [34,39]. In addition, galectin-3 can also be a potential treatment target for fibrosis. Several galectin-3 inhibitors are being developed in experimental studies [39]. In addition, other new bio- markers, such as procalcitonin, mid-regional pro-atrial NP, and growth differentiation factor-15, are also under investigation $[34,40]$. Individual novel biomarkers may not be useful as prognostic indicators, but combinations of these biomarkers can show better performance in the prediction of mortality [41].

Nevertheless, the results of studies regarding biomarker-guided therapy were variable [42]. NP-guided pharmacological therapy reduced all-cause mortality and HF hospitalization in a meta-analysis of 2,686 patients with chronic HF [43]. However, Guiding Evidence Based Therapy Using Biomarker Intensified Treatment in Heart Failure (GUIDE-IT), the most recent multi-center randomized controlled trial (RCT), yielded disappointing results. In that study, NT-proBNP-guided therapy did not show significant benefits compared with usual care in high-risk HFrEF patients [44]. There were a number of possible reasons for this failure, including: (1) the patients allocated to the biomarker-guided group in the clinical trials already had a low level of NP because they generally received strict guideline-directed medical therapy (GDMT) in advance; (2) the additional treatment in patients with high NP levels was limited to increases or addition of diuretics; and (3) it was not clear how much low NP level is needed to improve the patient outcomes. Therefore, it would be erroneous to conclude that biomarker-guided therapy is useless. GDMT has not been used in real-world situations due to the gap between guidelines and clinical practice $[45,46]$. Thus, biomarker-guided therapy may still have room for improvement.

\section{Genetic testing}

Inherited cardiomyopathies account for a small portion of HF cases. However, such cases cannot be ignored because the diagnosis, clinical manifestations, and treatment are different from those of other types of HF. For example, a patient with Anderson-Fabry disease can show systemic manifestations, including chronic kidney disease with proteinuria and stroke. The diagnosis requires confirmation by a specific test for enzyme activity or genetic testing and should be treated with enzyme replacement therapy [47]. Accordingly, genetic testing provides accurate information regarding the etiology of HF, potentially followed by a specific therapy and better clinical outcome $[48,49]$. 
Recently, the Heart Failure Society of America published new guidelines for genetic testing in patients diagnosed with genetic cardiomyopathy [50]. The guidelines were developed according to evidence about the validity and influence of genetic testing on the prognosis of diseases. Briefly, genetic testing is recommended in patients with hypertrophic cardiomyopathy (HCM), NIDCM, arrhythmogenic right ventricular cardiomyopathy, cardiomyopathy with other extracardiac manifestations, and LV non-compaction. Careful family history taking, phenotypic screening, and genetic counseling are recommended for family members of patients with genetically confirmed inherited cardiomyopathies.

In addition, a new classification method of genetic cardiomyopathy was proposed. Traditionally, the type of cardiomyopathy was defined by morphology, i.e., dilated, hypertrophic, and restricted cardiomyopathy. The European and American guidelines utilized complex classification methods because a wide variety of mutations as well as non-genetic cardiomyopathy can show similar findings [51,52]. Recent progress in testing methods, such as next-generation sequencing, revealed that several genetic mutations are responsible for single inherited cardiomyopathy and that there are many subclinical mutation carriers in the population. Therefore, a new classification incorporating these factors was required. The MOGE(S) classification includes morphofunctional phenotype $(\mathrm{M})$, involved organ system $(\mathrm{O})$, genetic inheritance pattern (G), etiology (E), and functional status (S) of the disease. This new classification integrates the phenotype, genotype, and function of an individual patient. Therefore, it has advantages regarding standardization and expandability of nomenclature [53].

\section{PHARMACOLOGICAL TREATMENT}

\section{Conventional pharmacological treatment}

Pharmacological treatment of HF has been evolving through increased understanding of its pathophysiology and the development of new drugs (Table 1 [54-89], Fig. 3). Before the 1980s, treatment of HF largely depended on bed rest and fluid restriction, and only digitalis and diuretics were prescribed for HF patients. As decreased LV contractility was thought to be the main cause of $\mathrm{HF}$, there were many attempts to improve contractility by administration of inotropic drugs to HF patients. However, most clinical trials of inotropic agents were stopped prematurely because of their poor results [90]. From the mid-1970s, vasodilators have been used to increase cardiac efficiency by reducing afterload, and the first large RCT of vasodilator treatment in HF was published in 1986. In this study, vasodilator treatment improved mortality, but subsequent larger studies suggested that it was not beneficial for the long-term survival of HF patients [54].

Since the 1980s, HF has been understood as a neurohormonal disease, and physicians attempted to improve cardiac function by blocking the renin-angiotensin-aldosterone system and sympathetic activation. ACEI was reported to reduce mortality and hospitalization in HFrEF patients [91], and $\beta$-blockers also improved LV function and reduced mortality and hospitalization rates [92]. Unlike ACEI, $\beta$-blockers do not have a class effect, and evidence of beneficial effects in treatment of HF have been reported only for bisoprolol, sustained-release metoprolol, carvedilol, and nebivolol $[93,94]$. Subsequently, additional prognostic benefits were reported when MRA was combined with ACEI and $\beta$-blocker therapy [95]. Angiotensin receptor blockers also showed beneficial effects on prognosis in patients with HFrEF and has been used as an alternative treatment option when ACEI cannot be used [96]. Combination therapy targeting the neurohormonal system significantly improved the prognosis of patients with HFrEF compared to the use of vasodilator and inotropic agents and is still the mainstay of pharmacological treatment of $\mathrm{HF}$ [94].

In the 200os, several new medications were introduced for treatment of HF. Ivabradine is an inhibitor that acts on the $I_{\mathrm{f}}$ channel of the sinoatrial node, which reduces heart rate independently of $\beta$-blocker use. In patients with HFrEF, ivabradine improves the clinical outcome in cases with resting heart rate $>70 \mathrm{bpm}$ despite adequate $\beta$-blocker therapy [55]. Tolvaptan is an oral vasopressin-2 receptor antagonist with excellent diuresis activity and is expected to be beneficial in decongestion of acute heart failure (AHF) patients [97]. As many AHF patients have renal dysfunction, resistance to diuretics, and electrolyte imbalance such as hyponatremia, tolvaptan seemed to be more beneficial in these patients [98]. However, tolvaptan failed to show a posi- 


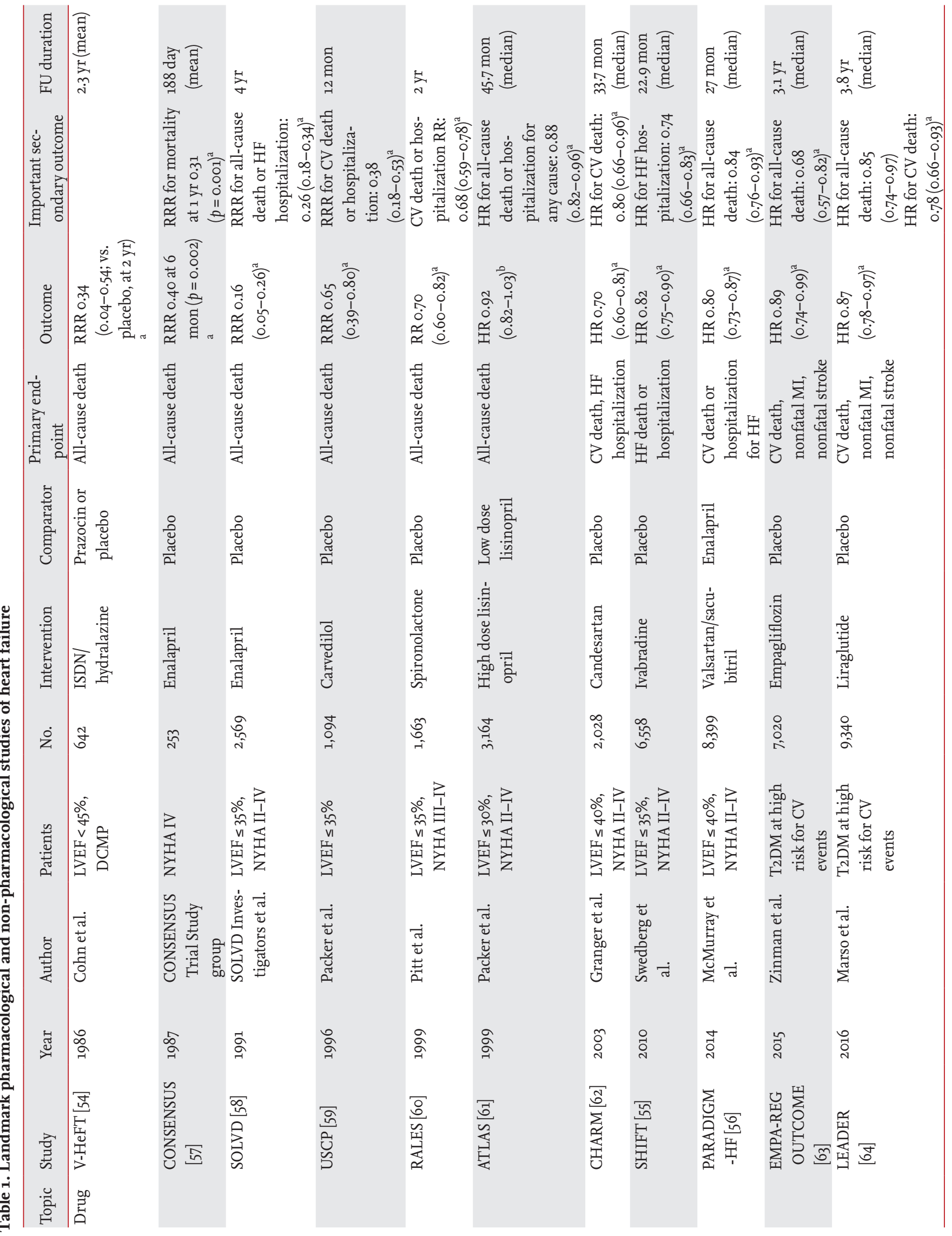




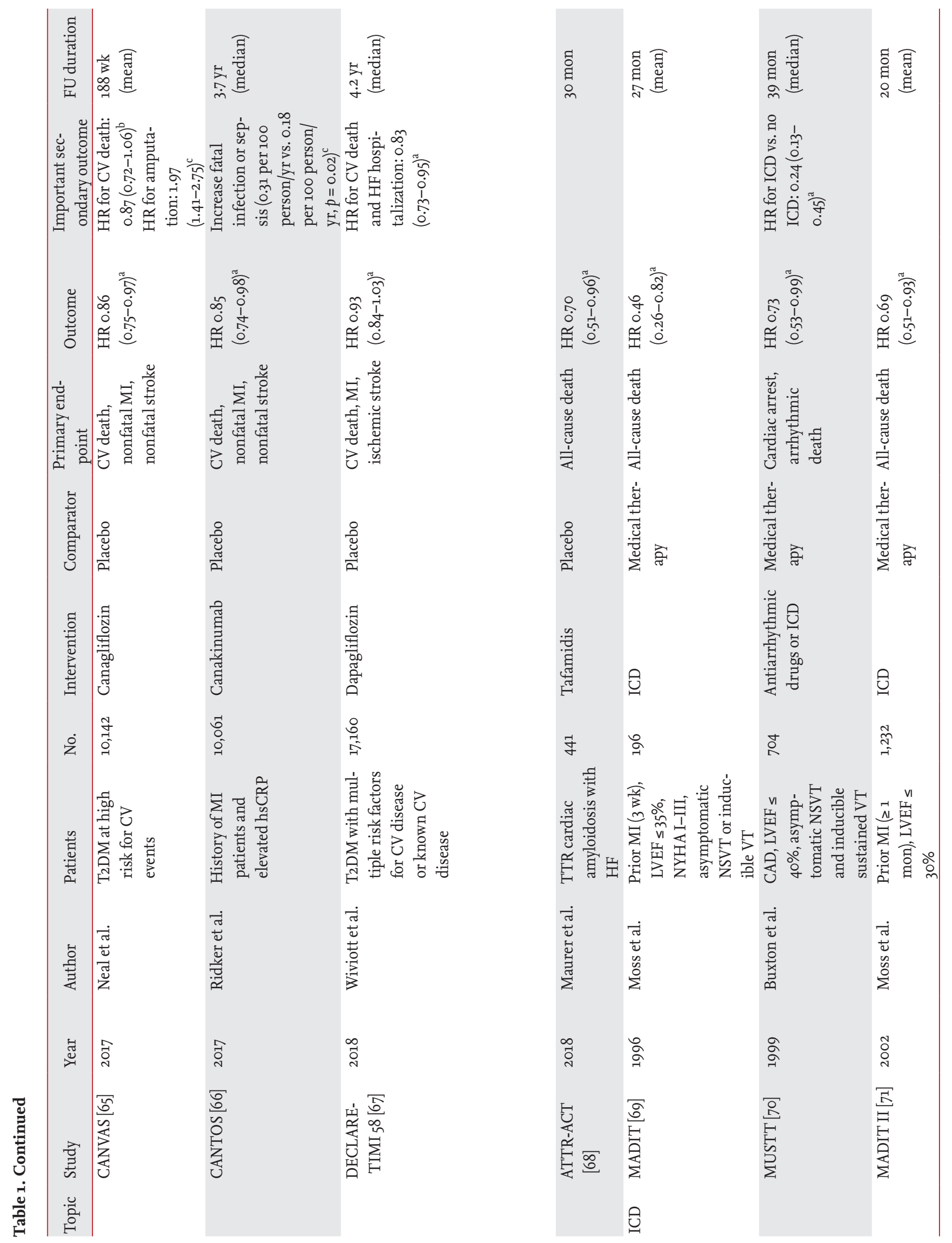




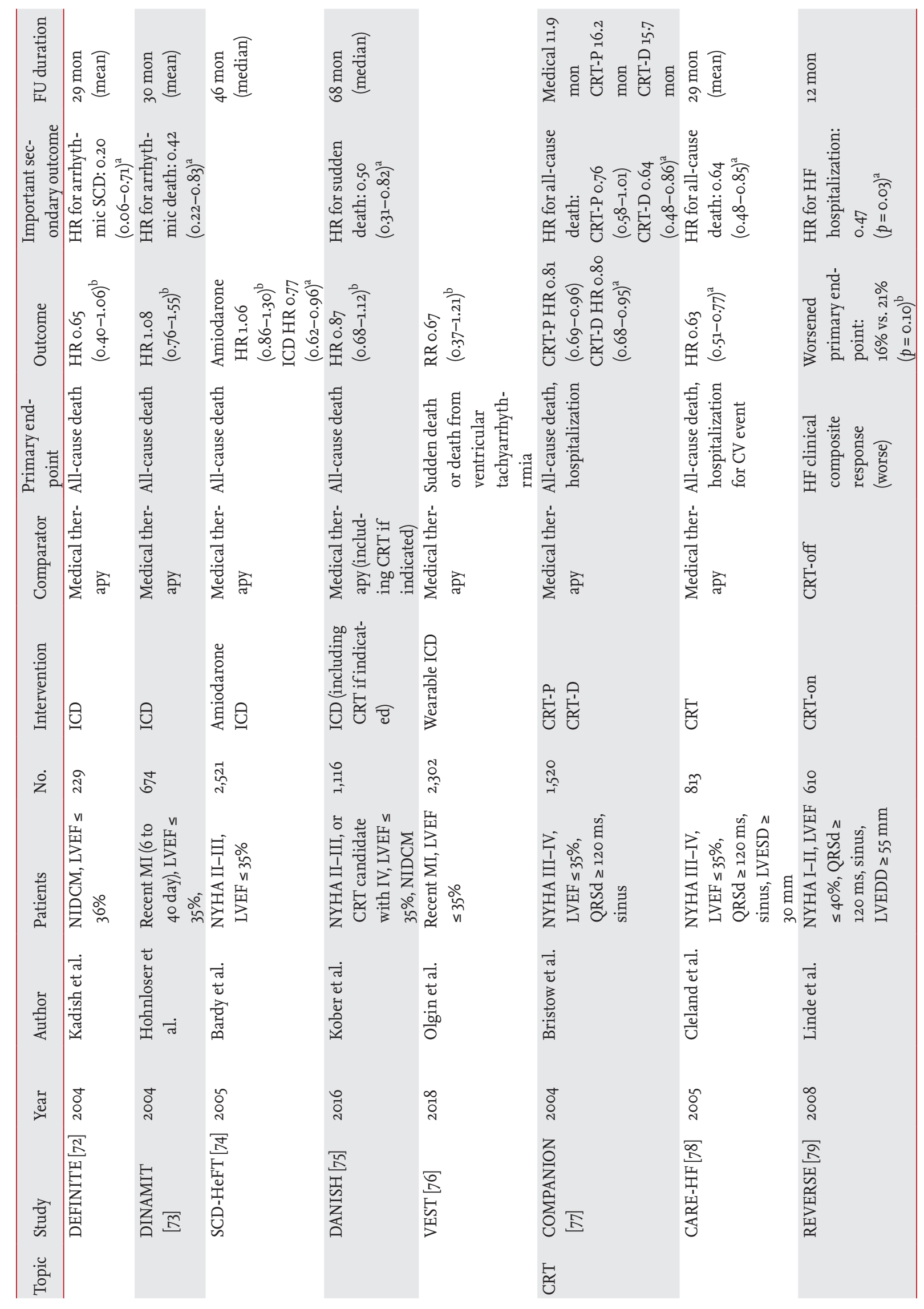




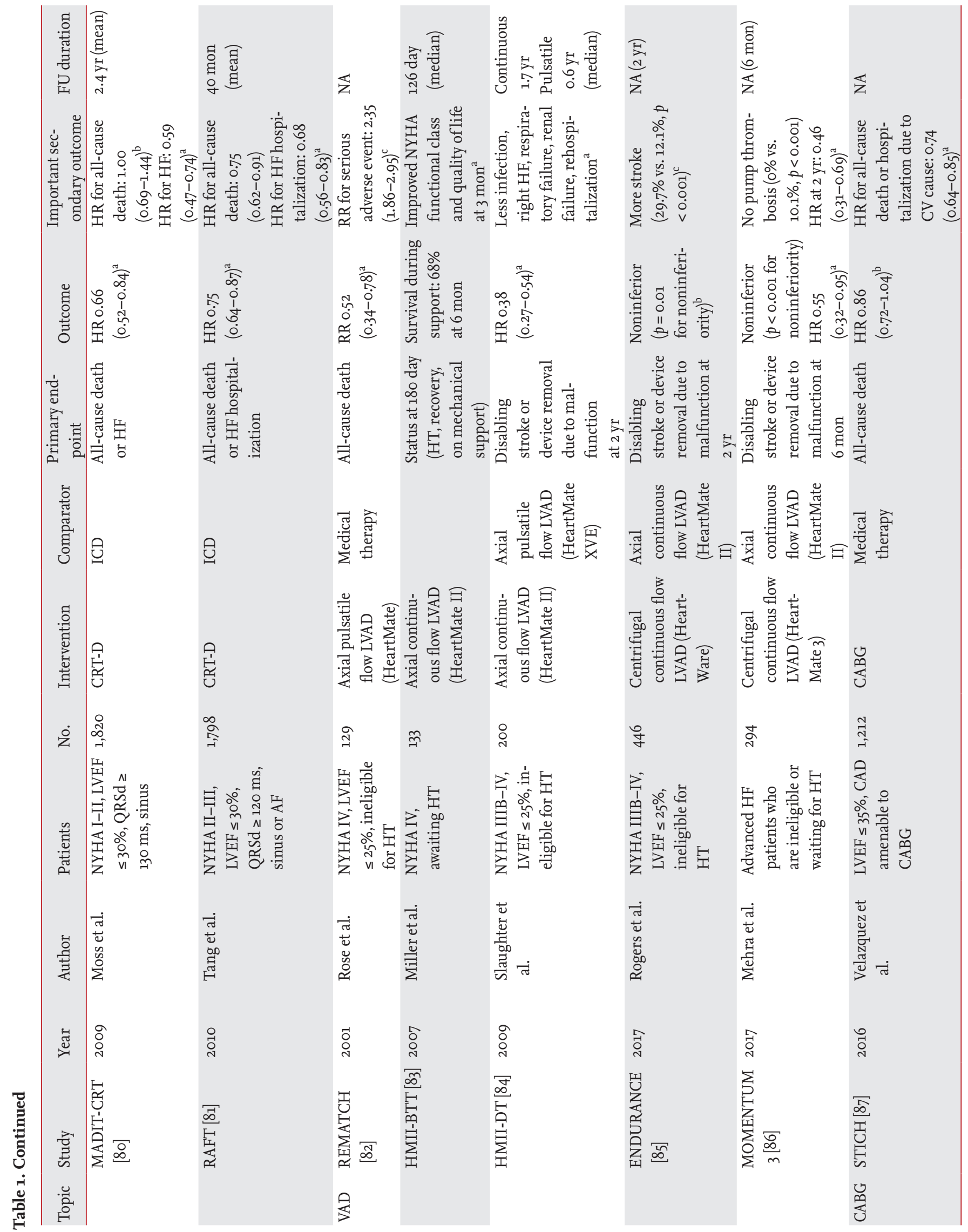




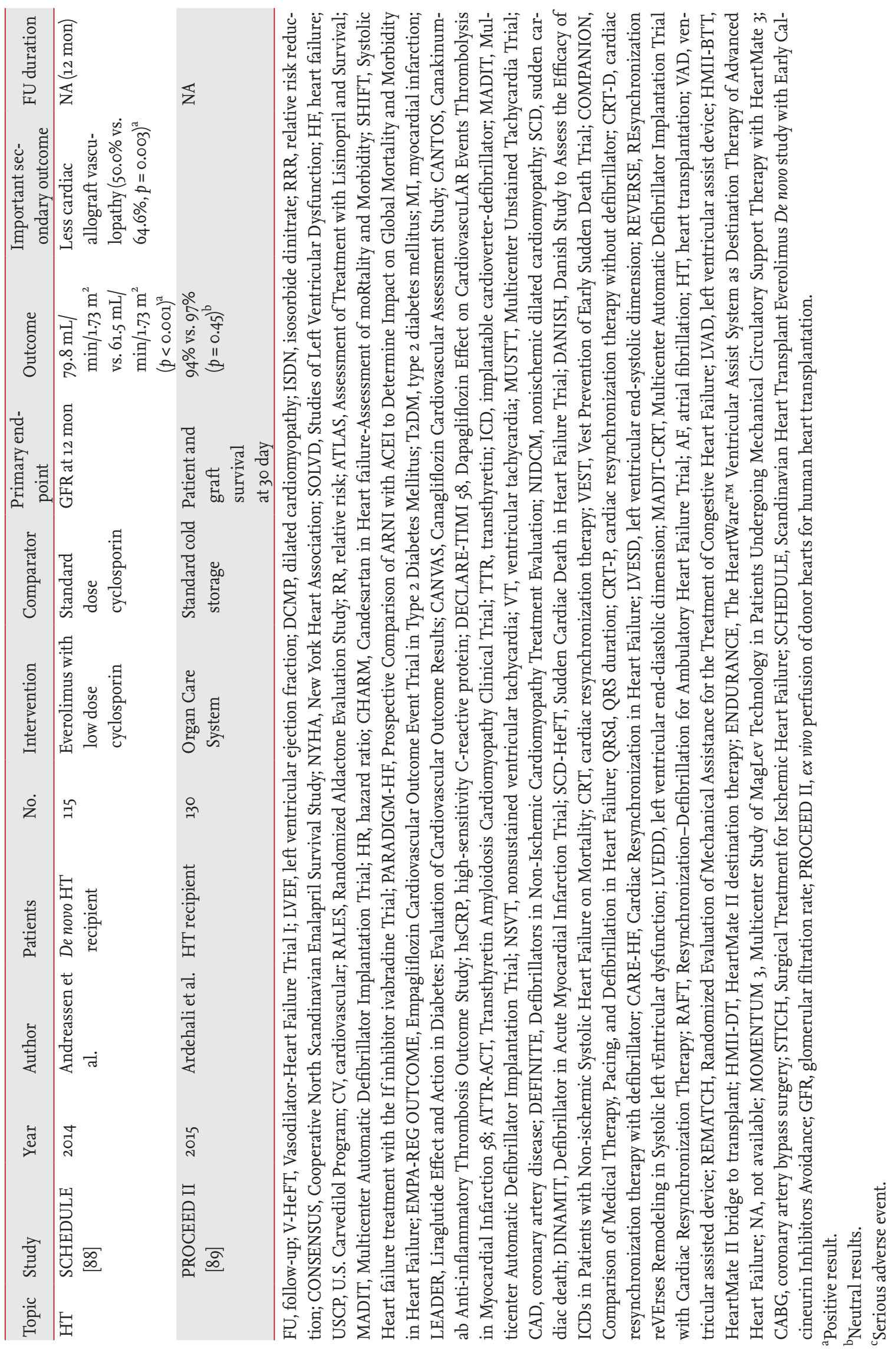




\begin{tabular}{|c|c|c|}
\hline & 1970-1979 & 1980-1983 \\
\hline & & Digoxin \& Diuretics \\
\hline 1960-1969 HT Ist TAH & & Cyclosporin \\
\hline
\end{tabular}

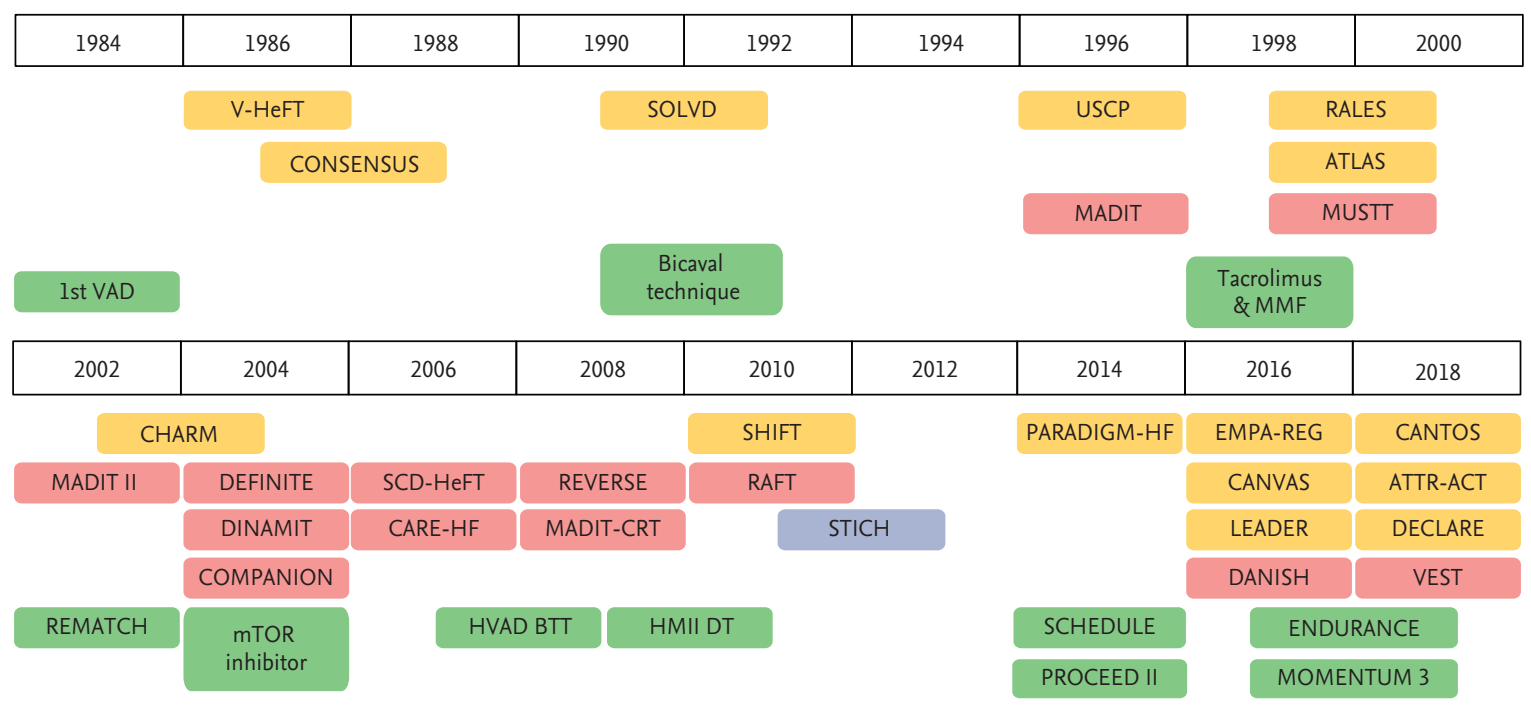

\begin{tabular}{|c|}
\hline Pharmacologic treatment \\
\hline ICD \& CRT \\
\hline VAD \& HT \\
\hline
\end{tabular}

Figure 3. Progression of heart failure treatment: medications, devices, and transplantation. HT, heart transplantation; TAH, total artificial heart; V-HeFT, Vasodilator-Heart Failure Trial I; CONSENSUS, Cooperative North Scandinavian Enalapril Survival Study; SOLVD, Studies of Left Ventricular Dysfunction; USCP, U.S. Carvedilol Program; RALES, Randomized Aldactone Evaluation Study; ATLAS, Assessment of Treatment with Lisinopril and Survival; MADIT, Multicenter Automatic Defibrillator Implantation Trial; MUSTT, Multicenter Unstained Tachycardia Trial; VAD, ventricular assisted device; MMF, mycophenolate mofetil; CHARM, Candesartan in Heart failure-Assessment of moRtality and Morbidity; SHIFT, Systolic Heart failure treatment with the $\mathrm{I}_{\mathrm{f}}$ inhibitor ivabradine Trial; PARADIGM-HF, Prospective Comparison of ARNI with ACEI to Determine Impact on Global Mortality and Morbidity in HF; EMPA-REG, Empagliflozin Cardiovascular Outcome Event Trial in Type 2 Diabetes Mellitus; CANVAS, Canagliflozin Cardiovascular Assessment Study; LEADER, Liraglutide Effect and Action in Diabetes : Evaluation of Cardiovascular Outcome Results; CANTOS, Canakinumab Anti-inflammatory Thrombosis Outcome Study; ATTR-ACT, Transthyretin Amyloidosis Cardiomyopathy Clinical Trial; DECLARE, Dapagliflozin Effect on CardiovascuLAR Events; DEFINITE, Defibrillators in Non-Ischemic Cardiomyopathy Treatment Evaluation; DINAMIT, Defibrillator in Acute Myocardial Infarction Trial; COMPANION, Comparison of Medical Therapy, Pacing, and Defibrillation in Heart Failure; SCD-HeFT, Sudden Cardiac Death in Heart Failure Trial; CARE-HF, Cardiac Resynchronization in Heart Failure; REVERSE, REsynchronization reVErses Remodeling in Systolic left vEntricular dysfunction; MADIT-CRT, Multicenter Automatic Defibrillator Implantation Trial with Cardiac Resynchronization Therapy; RAFT, Resynchronization-Defibrillation for Ambulatory Heart Failure Trial; STICH, Surgical Treatment for Ischemic Heart Failure; DANISH, Danish Study to Assess the Efficacy of ICDs in Patients with Non-ischemic Systolic Heart Failure on Mortality; VEST, Vest Prevention of Early Sudden Death Trial; REMATCH, Randomized Evaluation of Mechanical Assistance for the Treatment of Congestive Heart Failure; mTOR, mammalian target of rapamycin; HVAD BTT, HeartWare ventricular assist device bridge to transplant; HMII-DT, HeartMate II destination therapy; SCHEDULE, Scandinavian Heart Transplant Everolimus De novo study with Early Calcineurin Inhibitors Avoidance; PROCEED II, ex vivo perfusion of donor hearts for human heart transplantation; ENDURANCE, The HeartWare $^{\text {TM }}$ Ventricular Assist System as Destination Therapy of Advanced Heart Failure; MOMENTUM 3, Multicenter Study of MagLev Technology in Patients Undergoing Mechanical Circulatory Support Therapy with HeartMate 3; ICD, implantable cardioverter-defibrillator; CRT, cardiac resynchronization therapy. 
tive result in several clinical trials in AHF, and further studies are needed, therefore, to determine its applicability in the treatment of HF [99].

The Prospective Comparison of ARNI with ACEI to Determine Impact on Global Mortality and Morbidity in HF (PARADIGM-HF) study published in 2014 demonstrated the clinical efficacy of angiotensin receptor-neprilysin inhibitor (ARNI) in HFrEF [56]. ARNI is a combination of valsartan and the neprilysin inhibitor, sacubitril. Neprilysin is an endopeptidase that degrades several endogenous vasoactive peptides, including NPs, bradykinin, and adrenomedullin. Sacubitril increases the concentrations of these peptides by inhibiting neprilysin, and peptides antagonize the opposite action of neurohormonal overactivation [100]. Experimental studies have suggested that simultaneous inhibition of the renin-angiotensin system and neprilysin can more effectively decrease neurohormonal activation, which aggravates HF. As the combination of ACEI and sacubitril increased serious angioedema, valsartan and sacubitril constituted ARNI. In a large double-blind RCT, ARNI was superior to ACEI alone in reducing the risk of death and hospitalization for HFrEF patients [56]. ARNI is already being used for HFrEF patients as a standard practice, and clinical trials are underway regarding the role of ARNI in HFpEF patients and postMI patients.

While there have been steady developments regarding pharmacological treatment for use in patients with HFrEF, no drugs have shown clear mortality benefits in patients with HFpEF. At present, drug therapy in HF$\mathrm{pEF}$ is focused on controlling symptoms and treating risk factors and comorbidities [12].

\section{Emerging pharmacological treatment}

SGLT-2 inhibitor and glucagon-like peptide 1 agonist

The SGLT-2 inhibitors represent a novel class of antihyperglycemic agents that increase urinary excretion of glucose in the renal tubules [101]. Empagliflozin showed good outcomes in large RCT (Empagliflozin Cardiovascular Outcome Event Trial in Type 2 Diabetes Mellitus Patients [EMPA-REG OUTCOME]). Empagliflozin reduced HF hospitalization and cardiovascular death in patients with type 2 diabetes, with a consistent benefit in patients with HF. The serious adverse event rate of empagliflozin was similar, but the rate of genital infection was higher than placebo [63]. Canagliflozin also reduced the risk of cardiovascular death and hospitalization due to $\mathrm{HF}$ in patients with type 2 diabetes and elevated risk of cardiovascular disease (Canagliflozin Cardiovascular Assessment Study [CANVAS] trial). However, administration of canagliflozin increased the incidence of volume depletion, fracture, and amputation compared with placebo [65]. In addition, dapagliflozin also reduced the rates of cardiovascular death and hospitalization for HF in a recent RCT (Dapagliflozin Effect on Cardiovascular Events-Thrombolysis in Myocardial Infarction 58 [DECLARE-TIMI 58]) [67].

SGLT-2 inhibitors induce glycosuria and diuresis, which can be expected to reduce blood pressure, improve glycemic control, result in weight loss, and improve insulin sensitivity [102]. In addition, it has been reported that SGLT-2 inhibitors have cardioprotective effects by improving cardiac metabolism. A study in a murine model showed that empagliflozin increases cardiac adenosine triphosphate (ATP) production by activating cardiac oxidation of glucose and fatty acids [103], although the precise underlying mechanism is not fully understood yet.

Large-scale cardiovascular outcome studies using other SGLT-2 inhibitors are underway [104], and a multinational observational study, including South Korea, is currently in progress [105,106]. Moreover, the benefit of SGLT-2 inhibitors may persist regardless of the presence of diabetes. Empagliflozin significantly reduced the rate of cardiac deterioration in HF without diabetes in a murine model [107]. Human clinical studies on the effects of SGLT-2 inhibitors in HF without diabetes are also underway; DAPA-HF (NCT03036124) for dapagliflozin, EMPEROR-Reduced (NCTo3057977) and EMPEROR-Preserved (NCT03057951) for empagliflozin [108].

Liraglutide, a glucagon-like peptide 1 analog, showed decreased all-cause mortality and cardiovascular death compared with placebo in a large-scale RCT [64]. As the U.S. Food and Drug Administration requires cardiovascular safety data for any new antidiabetic medications before approval, novel antidiabetic medications with additional cardiovascular benefits are likely to be developed in the future as well. 
New drugs in specific cardiomyopathy fields

New drugs that act on cardiac myosin have been developed and tested for efficacy in specific diseases. Mavacamten, which acts as an inhibitor of cardiac myosin ATPase and reduces cardiac contractility, is under investigation in patients with obstructive HCM [109]. PIONEER-HCM (NCTO2842242) is a phase 2 trial of mavacamten. In a pilot study performed in 11 patients with symptomatic obstructive HCM, significant decreases in both post-exercise peak and resting LV outflow tract gradient were observed in patients with mavacamten treatment [110]. With these positive results, a phase 3 study of EXPLORER-HCM is currently underway (NCT03470545).

In contrast to mavacamten, omecamtiv mecarbil (OM) is a selective cardiac myosin activator that increases myocardial systolic function. When administered to patients with AHF, the clinical effect of OM in relieving dyspnea was not clear (Acute Treatment With Omecamtiv Mecarbil to Increase Contractility in Acute Heart Failure [ATOMIC-AHF]) [111]. However, patients with chronic HF showed positive results after OM treatment with increased cardiac function, decreased ventricular dimension, and decreased serum NT-proBNP level (Chronic Oral Study of Myosin Activation to Increase Contractility in Heart Failure [COSMIC-HF]) [112]. The Global Approach to Lowering Adverse Cardiac Outcomes Through Improving Contractility in Heart Failure (GALACTIC-HF; NCTo2929329) trial is currently underway to determine the clinical role of $\mathrm{OM}$ in comparison with placebo when added to current HF standard medication in patients with chronic HF [113].

The Transthyretin Amyloidosis Cardiomyopathy Clinical Trial (ATTR-ACT) showed remarkable results in transthyretin amyloid cardiomyopathy. Fibrillogenesis in amyloid cardiomyopathy occurs when the tetrameric structure of the transthyretin protein dissociates into intermediates, which misassemble into amyloid fibrils. Tafamidis binds to the thyroxine-binding sites of transthyretin with high affinity and selectivity, and inhibits dissociation of tetramers into monomers. In this multicenter, double-blind RCT, tafamidis showed reductions in all-cause mortality and cardiovascular-related hospitalization rates and reduced the decline in functional capacity compared with placebo [68].
Anti-inflammatory therapy

Various cytokines have been shown to play important roles in determining cardiac function under pathophysiological conditions. Several cytokines, including tumor necrosis factor $\alpha$, transforming growth factor $\beta$, and interleukins (ILs), such as IL-1, IL-4, IL-6, IL-8, and IL-18, are involved in the development of various inflammatory cardiac pathologies. There have been many clinical trials to improve cardiac pathology by blocking these cytokines, but most have failed to demonstrate clinical efficacy [114].

Anti-inflammatory therapy using canakinumab, a monoclonal antibody targeting IL-1 $\beta$, led to a significantly lower rate of recurrent cardiovascular events in patients with previous MI compared to placebo. However, because canakinumab caused serious infectious complications, the all-cause mortality rate was not different from the placebo group (Canakinumab Anti-inflammatory Thrombosis Outcome Study [CANTOS] trial) [66]. The IL-1 receptor antagonist, anakinra, is another potential candidate for anti-inflammatory therapy. Administration of anakinra showed improvement of peak $\mathrm{VO}_{2}$ in recently decompensated systolic HF patients (Recently Decompensated Heart Failure Anakinra Response Trial [REDHART]) [115], but did not lead to changes in HFpEF patients (Decompensated Heart Failure Anakinra Response Trial 2 [DHART2]) [116]. It is unclear whether anakinra is effective in preventing cardiac remodeling after acute MI, but a multicenter, double-blind placebo-controlled clinical trial is currently underway (Virginia Commonwealth University-Anakinra Remodeling Trial $_{3}$ [VCU-ART3] trial; NCTo1950299) [117].

\section{Gene therapy}

Cardiac gene therapy, involving the production of proteins with curative efficacy by transferring specific exogenous genes, was proposed as an important alternative therapeutic approach [118]. The major targets of gene therapy are the $\beta$-adrenergic system, angiogenesis, cytoprotection, and stem cell homing, among which research on $\mathrm{Ca}^{2+}$ cycling protein is a representative project. The sarcoplasmic/endoplasmic reticulum $\mathrm{Ca}^{2+}$-ATPase (SERCA2a) regulates the contraction and relaxation of myocardial cells by transporting calcium into the sarcoplasmic reticulum from the cytosol. Regardless of the etiology, it has been demonstrated that SERCA2a is 
deficient in experimental models of $\mathrm{HF}$, and correction of SERCA2a deficiency can improve calcium influx and cardiac function. However, a recent study showed that administration of SERCA2a does not improve the clinical course of HFrEF patients [119]. Despite disappointing results, gene therapy still has potential and further studies are required. One of the major obstacles to gene therapy is the delivery method of the therapeutic materials into the target cells. As intravenous injection did not show sufficient effect to transduce the myocardium, intracoronary injection, myocardial injection, and pericardial injection have been suggested according to the condition of the patient, the type of vector, and the target gene. Further advances in vectors and delivery methods will be essential for the clinical application of gene therapy [120].

\section{Stem cell therapy}

As there is no alternative way to regenerate or replace damaged cardiomyocytes, there has been a great deal of interest in the development of stem cell therapy [121]. Numerous studies yielded optimistic results using stem cells to improve myocardial function and ventricular remodeling, but the results were inconsistent [122]. Human pluripotent stem cells (hPSCs) have emerged to replace embryonic stem cells, which maintain the similarity to embryonic stem cells but without the ethical issues or risks of rejection [123]. The efficiency of differentiation from hPSCs to cardiomyocytes and bioengi- neering technology to improve the therapeutic effects of hPSC-derived cardiomyocytes have improved over the past several decades. However, cellular heterogeneity, immaturity, arrhythmogenicity, and tumorigenicity are problems that remain to be resolved [123].

\section{DEVICES AND NON-SURGICAL INTERVENTIONS}

\section{Implantable cardioverter-defibrillator \& cardiac resynchronization therapy}

Many pioneering landmark trials from the 1990s have confirmed the efficacy of implantable cardioverter-defibrillator (ICD) and cardiac resynchronization therapy (CRT) for improving cardiovascular outcome in HF patients (Table 1, Fig. 3). Current ESC guidelines generally suggest ICD for primary prevention in symptomatic HF patients with $\mathrm{LVEF} \leq 35 \%$, despite $>3$ months of optimal medical therapy [1]. The detailed indications are slightly different according to the specific cardiomyopathy in patients (Table 2) [1,124,125]. For example, HCM with a high risk of sudden cardiac death, dilated cardiomyopathy due to lamin A/C (LMNA) mutation, cardiac sarcoidosis with unexplained syncope, or myocardial scarring seen on CMR, are indications for ICD regardless of LVEF [126]. However, the Danish Study to Assess the Efficacy of ICDs in Patients with Non-ischemic Systolic Heart Failure on Mortality (DANISH) trial, which

Table 2. Current class I indications of cardiac implantable electronic devices in patients with heart failure

\begin{tabular}{|c|c|c|c|}
\hline & $\begin{array}{l}\text { ICD for secondary } \\
\text { prevention }\end{array}$ & ICD for primary prevention & CRT \\
\hline $\begin{array}{l}\text { ACC/AHA (2013) } \\
{[125]}\end{array}$ & & $\begin{array}{l}\text { NIDCM or ICM at least } 40 \text { days post-MI on } \\
\text { chronic GDMT with (1) LVEF } \leq 35 \% \text { and } \\
\text { NYHA class II or III symptom (I-A) or }(2) \\
\text { LVEF } \leq 30 \% \text { and NYHA class I symptom (I-B) }\end{array}$ & $\begin{array}{l}\text { Sinus rhythm with LVEF } \leq 35 \% \text { on } \\
\text { GDMT and LBBB with QRSd } \geq 150 \\
\text { ms and NYHA class III (I-A) or am- } \\
\text { bulatory IV (I-A) or II (I-B) }\end{array}$ \\
\hline $\operatorname{ESC}(2016)[1]$ & $\begin{array}{l}\text { Recovery from ven- } \\
\text { tricular arrhythmia } \\
\text { with hemodynamic } \\
\text { instability (IA) }\end{array}$ & $\begin{array}{l}\text { Symptomatic HF (NYHA II-III) with LVEF } \leq \\
35 \% \text { despite } \geq 3 \text { months of OMT in ICM (IA) or } \\
\text { NIDCM (IB) }\end{array}$ & $\begin{array}{l}\text { Symptomatic HF with sinus rhythm } \\
\text { and LVEF } \leq 35 \% \text { despite OMT with } \\
\text { LBBB with QRSd } \geq 150 \mathrm{~ms} \text { (I-A) or } \\
\text { 130-149 } \mathrm{ms} \text { (I-B) }\end{array}$ \\
\hline
\end{tabular}

ICD, implantable cardioverter-defibrillator; CRT, cardiac resynchronization therapy; ACC/AHA, American College of Cardiology/American Heart Association; NIDCM, nonischemic dilated cardiomyopathy; ICM, ischemic cardiomyopathy; MI, myocardial infarction; GDMT, goal-directed medical therapy; LVEF, left ventricular ejection fraction; NYHA, New York Heart Association; LBBB, left bundle branch block; QRSd, QRS duration; ESC, European Society of Cardiology; HF, heart failure; OMT, optimal medical therapy. 


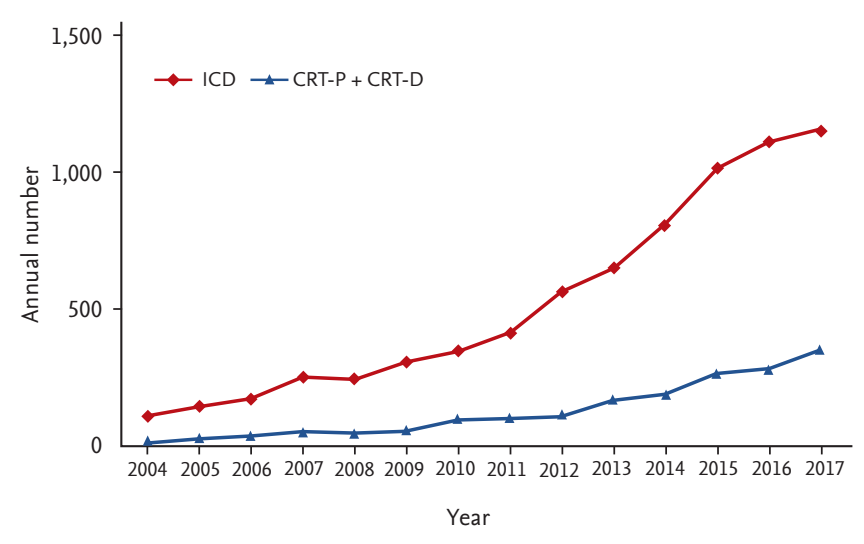

Figure 4. Temporal trends of cardiac implantable electronic device implantation in Korea. ICD, implantable cardioverter-defibrillator; CRT-P, cardiac resynchronization therapy without defibrillator; CRT-D, cardiac resynchronization therapy with defibrillator.

included 1,116 nonischemic cardiomyopathy patients, showed no mortality benefit with prophylactic ICD implantation [75], which reflects the different risk of sudden cardiac death in nonischemic cardiomyopathy and ischemic cardiomyopathy. However, as more than half of the patients received optimal medical therapy and CRT in both groups, this may have influenced the lack of significant results associated with prophylactic ICD. Therefore, the role of prophylactic ICD implantation to reduce mortality in HF patients may be reestablished with the further development of HF therapy. The application of wearable ICD in patients with recent MI and LVEF $\leq 35 \%$ did not show significant differences compared with GDMT, with regard to rates of sudden death or death from ventricular tachyarrhythmia at 90 days [76].

The generally accepted class I indications for CRT are restricted to symptomatic patients with LVEF $\leq 35 \%$, despite optimal medical therapy, who have left bundle branch block and QRS duration $\geq 130 \mathrm{~ms}$ [127]. In Korea, there has been a rapid increase in the implantation of cardiac implantable electronic devices (Fig. 4).

Recent studies have focused on determining ways to achieve a high response rate in patients with CRT implants. Based on LGE detected by CMR, which can directly visualize myocardial scarring, patients receiving LV lead placement away from LGE showed better clinical outcome [128]. In the Targeted Left Ventricular
Lead Placement to Guide Cardiac Resynchronization Therapy (TARGET) study, 220 patients were randomly assigned to two groups with or without targeted LV lead deployment using speckle-tracking 2-dimensional radial strain measured by transthoracic echocardiography. The targeted LV lead placement group showed a higher portion of CRT responders and lower rate of combined endpoint compared with the control group [129]. The combination of multimodality imaging, including nuclear imaging and radial strain, demonstrated a higher response rate compared with the control group, but the clinical outcomes were similar between the two groups [130].

\section{Role of AF ablation in HF}

AF is the most common type of arrhythmia in HF populations, and it can cause deterioration of LV function as well as symptoms of HF [131]. Rate control and anticoagulation are the mainstays of AF treatment. The 2016 ESC guidelines specify that a rhythm control strategy using amiodarone or AF ablation may be considered in chronic AF patients with HFrEF who are symptomatic despite optimal medical therapy (Class IIb) [1]. However, a recently published RCT showed a beneficial effect of AF ablation in HFrEF patients compared with pharmacological control (Catheter Ablation for Atrial Fibrillation with Heart Failure [CASTLE-AF] trial). In this RCT, patients who received AF ablation therapy showed lower rates of all-cause mortality, worsening or hospitalization for HF, and cardiovascular death after about 3 years [132]. Another RCT (Ablation versus Amiodarone for Treatment of Atrial Fibrillation in Patients With Congestive Heart Failure and an Implanted ICD/CRTD [AATAC] trial) showed that AF ablation was superior to amiodarone treatment with regard to maintenance of sinus rhythm, unplanned hospitalization, and mortality [133]. However, the CASTLE-AF trial included a highly selected population $(398$ of 3,013 screened patients), and a beneficial effect of AF ablation was observed in patients with young age $(<65$ years), NYHA functional class II, LVEF $\geq 25 \%$, and without diabetes [132]. The results of the Catheter Ablation Versus Anti-arrhythmic Drug Therapy for Atrial Fibrillation (CABANA) trial (NCToo911508), which enrolled 2,204 patients $\geq 65$ years or with more than one risk factor for stroke, did not show a beneficial effect of $\mathrm{AF}$ 
ablation in patients with high risk of stroke. The composite primary endpoints consisting of death, disabling stroke, serious bleeding, or cardiac arrest at 5 years were similar between ablation and drug therapy groups (hazard ratio, 0.86; $95 \%$ confidence interval, 0.65 to 1.15 for intention-to-treat analysis) [134]. If a patient has HF and symptomatic AF but is not a candidate for AF ablation or has failed to respond to this treatment, atrioventricular junction ablation followed by CRT may be a useful treatment option. Despite the small size of the study population, the Ablate and Pace in Atrial Fibrillation plus Cardiac Resynchronization Therapy (APAF-CRT) trial showed a decreased rate of hospitalization for HF and improved quality of life in patients undergoing atrioventricular junction ablation and CRT [135].

\section{Remote monitoring}

Remote monitoring has become one of the most active fields in the management of HF. Due to the importance of volume status in HF patients, there have been efforts to estimate and use hemodynamics as a guide for treatment. The CardioMEMS (St. Jude Medical, St. Paul, MN, USA) Heart Sensor Allows Monitoring of Pressure to Improve Outcomes in NYHA Class III Heart Failure Patients (CHAMPION) trial, a prospective RCT enrolling 550 symptomatic patients with chronic HF regardless of LVEF, showed that hemodynamic monitoring with a wireless implantable pulmonary artery pressure monitoring system (CardioMEMS) could significantly reduce HF hospitalization rate [136]. In the subgroup of 445 HFrEF patients on GDMT in the CHAMPION study, pulmonary artery pressure-guided management also reduced HF hospitalization and mortality rates [137]. Based on the previous results, CardioMEMS was approved by the U.S. Food and Drug Administration in 2014 and was included in the 2016 European guideline (Class IIb) [1].

Large amounts of information are available from patients with a preexisting cardiac implantable electronic device, including heart rate, lead profile, battery status and arrhythmic events. In the INfluence of home moniToring on mortality and morbidity in heart failure patients with IMpaired lEft ventricular function (INTIME) trial, without the need for additional invasive procedures, 664 patients with LVEF $\leq 35 \%$ implanted with ICD or CRT were randomized into two groups with or without telemonitoring, and a significantly lower rate of clinical composite endpoint was observed in the telemonitoring group at 1 year [138]. Remote monitoring also decreased the time to clinical decision and the length of hospital stay for cardiovascular hospitalization in the Clinical Evaluation of Remote Notification to Reduce Time to Clinical Decision (CONNECT) trial [139]. However, a meta-analysis including nine RCTs of remote monitoring showed no additional benefit with regard to survival or patient safety [140].

The diagnostics included in implantable devices show good predictive capability for impending HF decompensation using device-specific algorithms, such as OptiVol (Medtronic, Minneapolis, MN, USA) [141]. However, the OptiLink HF study did not show a significant difference in mortality according to alerts regarding changes in intrathoracic impedance reflecting patients' fluid status [142]. The Multisensor Chronic Evaluation in Ambulatory Heart Failure Patients (MultiSENSE) study showed that HeartLogic multisensory index and alert algorithm (Boston Scientific, Marlborough, MA, USA) can be a good predictor of HF decompensation [143]. Based on these findings, the Multiple Cardiac Sensors for Management of Heart Failure (MANAGE-HF) trial in which patients were randomized according to whether HeartLogic alerts were turned on or off is currently ongoing (NCT03237858). As methodologies for remote monitoring using implantable devices can be extended, we expect better results in the near future.

\section{Percutaneous correction of functional mitral regurgitation}

Functional or secondary mitral regurgitation (MR), frequently accompanied by HFrEF, is a meaningful predictor of mortality after adjusting for clinical, echocardiographic, or laboratory variables [144]. However, surgical treatment of moderate ischemic MR in addition to coronary artery bypass surgery failed to show LV reverse remodeling and mortality improvement [145]. As the benefit of surgery for functional MR is questionable, the American guidelines for valvular heart disease published in 2014 recommended mitral valve surgery for secondary MR only in patients with symptomatic severe MR or moderate MR undergoing other cardiac surgery [146]. Percutaneous approaches to correct secondary MR in HF patients are actively studied because 
the devices for percutaneous treatment of MR have been advanced throughout repair, annuloplasty, and replacement of the mitral valve [147], and the surgical risk of HFrEF combined with MR is high. A recent RCT for severe secondary MR comparing percutaneous mitral valve repair using MitraClip with medical therapy versus medical therapy alone (Percutaneous Repair with the MitraClip Device for Severe Functional/Secondary Mitral Regurgitation [MITRA-FR]) showed similar mortality and HF hospitalization rates [148]. On the other hand, in the Cardiovascular Outcomes Assessment of the MitraClip Percutaneous Therapy for Heart Failure Patients with Functional Mitral Regurgitation (COAPT) trial performed in 614 symptomatic patients with HF and moderate-to-severe secondary MR despite maximal medical therapy, the addition of percutaneous mitral repair with MitraClip to medical therapy was associated with lower rates of HF hospitalization and all-cause mortality than medical therapy alone within 2 years of follow-up [149].

Other percutaneous approaches to improve the outcomes of functional MR are also under investigation. The outcomes with the Cardioband system, a device for percutaneous mitral annuloplasty, were reported recently. Most patients showed moderate or less residual MR and improved symptoms at 1 year [150]. The Annular ReduCtion for Transcatheter Treatment of Insufficient Mitral ValvE (ACTIVE) randomized trial is recruiting patients to evaluate the efficacy of the Cardioband system along with optimal medical therapy (NCTo3016975). Various devices for percutaneous mitral valve replacement are also under investigation but are still at the level of early feasibility studies at present $[151,152]$. Moreover, Neochord, which was developed for transapical repair of MR with artificial chordae, is also the subject of an RCT in comparison with surgical mitral valve repair in degenerative MR (NCTo2803957).

\section{Other interventions: inter-atrial shunting, vagus nerve stimulation, and others}

Several forward-looking device therapies are under development. The Reduce Elevated Left Atrial Pressure in Patients With Heart Failure (REDUCE LAP-HF) I study is a phase II RCT of an interatrial shunt in symptomatic HF patients with $\mathrm{LVEF} \geq 40 \%$ and elevated exercise pulmonary capillary wedge pressure. The device sig- nificantly reduced post-exercise pulmonary capillary wedge pressure at 1 month [153] and showed similar safety outcome at 1 year [154]. As autonomic imbalance is important in the pathophysiology of HF, vagus nerve stimulation is thought to be a potential treatment target [155]. Recent phase II (NEural Cardiac TherApy foR Heart Failure [NECTAR-HF]) [156,157] and phase III RCTs (Increase of Vagal Tone in Heart Failure (INOVATE-HF) [158] for symptomatic HF with LV dysfunction reported results of vagus nerve stimulation but failed to show significant decreases in LV end-systolic diameter or improvement of clinical outcomes.

Although renal denervation has been suggested as an alternative treatment option for resistant hypertension, the results of RCTs were disappointing [159,160]. However, another RCT indicated the possibility of revival. In the Renal Denervation With the Symplicity Spyral ${ }^{\text {TM }}$ Multi-electrode Renal Denervation System in Patients With Uncontrolled Hypertension in the Absence of Antihypertensive Medications (SPYRAL HTN-OFF MED) trial, the renal denervation group showed a decrease of about $5 \mathrm{mmHg}$ in systolic and diastolic blood pressure with 24-hour ambulatory blood pressure monitoring after 3 months, while the sham group showed no significant changes in blood pressure [161]. Two new RCTs for renal denervation have recently begun: endovascular ultrasound renal denervation to treat hypertension (RADIANCE-HTN SOLO; NCTo2649426) and SPYRAL HTNON MED (NCTo2439775). As hypertension is one of the most important etiologies of HF, renal denervation may be a promising technology if these trials succeed.

\section{MECHANICAL CIRCULATORY SUPPORT AND HEART TRANSPLANTATION}

\section{Mechanical circulatory support}

Left ventricular assist devices (LVAD) are rapidly being adopted for advanced HF treatment. These devices were initially used as a bridge to transplantation, but are now also commonly used as destination therapy. Advances in mechanical technology and surgical techniques have greatly increased the success rate and duration of ventricular assist devices. The HeartWare ventricular assist device (HVAD), which is a commercial LVAD using a centrifugal heart pump, showed a non-inferior outcome 

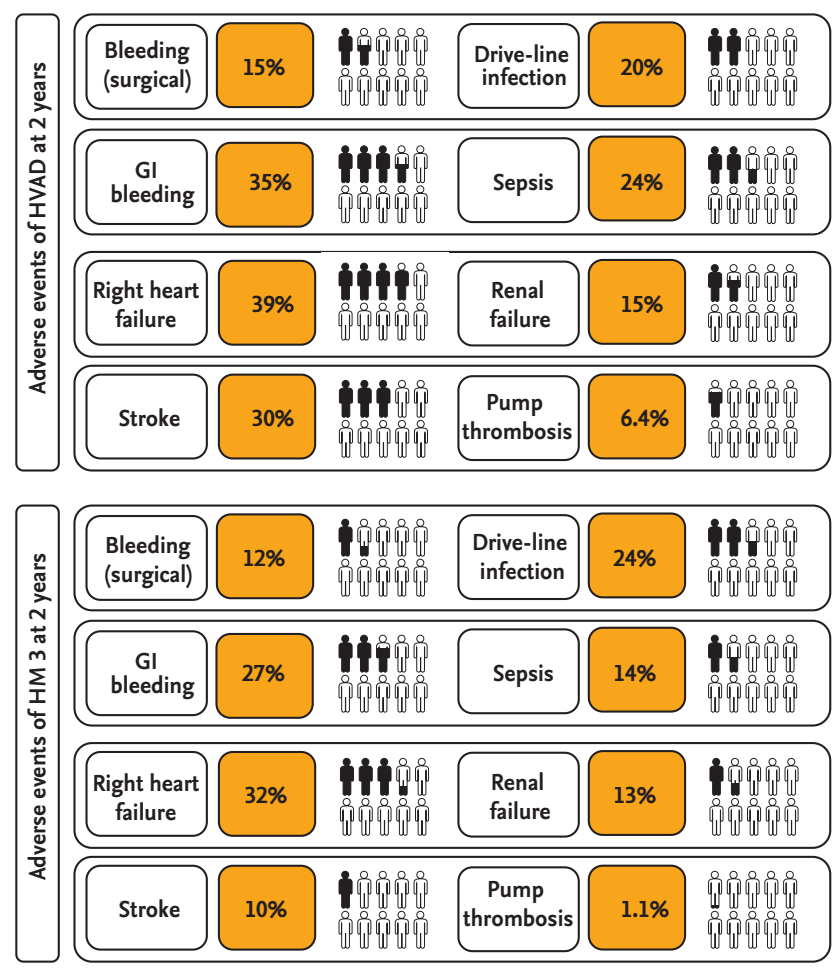

Figure 5. Adverse events of left ventricular assist devices. The data of HeartWare ventricular assist device (HVAD) and Heartmate 3 ( $\mathrm{HM}_{3}$ ) were quoted from different clinical trials, so direct comparison of adverse event rates is inappropriate. GI, gastrointestinal.

in comparison with Heartmate II (The HeartWare ${ }^{\text {TM }}$ Ventricular Assist System as Destination Therapy of Advanced Heart Failure [ENDURANCE]) [85]. This device is highly miniaturized to facilitate minimally invasive surgery and reduce surgical complications [162]. HVAD showed good clinical outcome and safety in the real-world registry data. Follow-up of 254 patients in a multicenter prospective registry study of patients transplanted with HVAD revealed a mean duration of support of $363 \pm 280$ days and success rates of $87 \%$ at 6 months, $85 \%$ at 1 year, and $73 \%$ at 3 years (post-market Registry to Evaluate the HeartWare Left Ventricular Assist System [ReVOLVE] study). During the follow-up period, $17 \%$ of the patients died, and the most common adverse event was bleeding (28\%). In particular, the relatively high incidence of cerebrovascular accidents after HVAD implantation in previous studies was reduced to acceptable levels in the ReVOLVE study. Vigorous anticoagulation therapy and adequate blood pressure control play important roles in reducing the incidence of stroke [163]. There have also been improvements in minimally invasive techniques to reduce surgical complications (Fig. 5) [164].

Heartmate II, another LVAD, also showed acceptable clinical outcomes and safety for destination therapy [84] as well as use as a bridge to transplantation [83]. The newly developed Heartmate 3 is equipped with a fully magnetically levitated centrifugal flow pump, and showed a survival rate of $77.9 \%$ without serious complications at 2 years after device implantation (Multicenter Study of MagLev Technology in Patients Undergoing Mechanical Circulatory Support Therapy with HeartMate 3 [MOMENTUM 3]) [165]. This is an improvement compared with $56.4 \%$ for the previous version, Heartmate II. Although the survival rate is improving, many patients with Heartmate 3 implants still experience a range of complications, including bleeding, infection, stroke, right HF, and arrhythmias (Fig. 5) [86,165].

SynCardia, a sole total artificial heart (TAH) approved by the U.S. Food and Drug Administration, provides the most definitive treatment options for patients with biventricular failure who are not candidates for isolated LVAD placement [166]. The SynCardia system has recently developed a smaller $50 \mathrm{cc}$ TAH that was designed to accommodate patients with low body surface area. This technical improvement should allow the device to be implanted in women and children, and it might be particularly useful in growing adolescents with palliated congenital heart disease [167].

\section{Heart transplantation}

Heart transplantation (HT) has become the standard treatment for selected patients with end-stage HF. Improvements in immunosuppressants, donor procurement, surgical techniques, and post-HT care have resulted in a substantial decrease in the incidence of acute allograft rejection, which had previously significantly limited survival of HT recipients. However, there are limitations to long-term allograft survival, including rejection, infection, coronary allograft vasculopathy, and malignancy (Fig. 6). Careful balance of immunosuppressive therapy and vigilant surveillance for complications can further improve long-term outcomes of HT recipients. Most transplant recipients have been treated with a combination of a calcineurin 

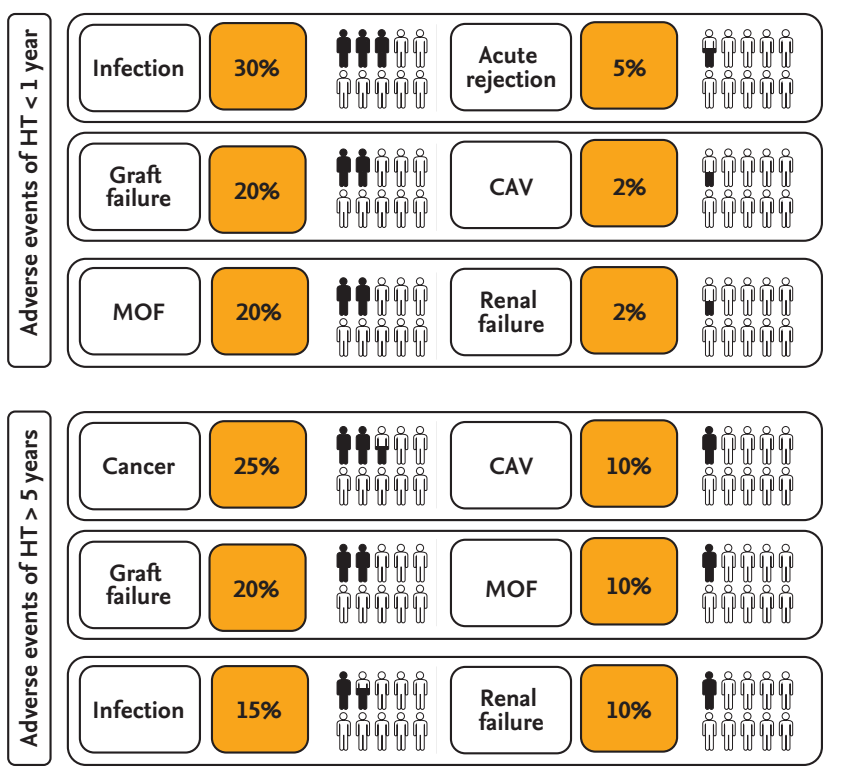

Figure 6. Adverse events of heart transplantation: within 1 year and after 5 years. HT, heart transplantation; MOF, multi-organ failure; CAV, cardiac allograft vasculopathy.

inhibitor, mycophenolate mofetil, and steroids [168]. To monitor the effects of immunosuppressive drugs and adjust the dose, physicians check the serum concentration of immunosuppressant. However, the serum concentration does not accurately reflect the degree of immunosuppression in a specific patient. Immune monitoring assay (Immuknow, Cylex, Columbia, MD, USA), a peripheral blood test, helps physicians to determine the degree of immunosuppression in patients by measuring the amount of ATP released from activated lymphocytes [169]. In a study to determine the efficacy of immune monitoring assay, patients with infectious complications had a low immune monitoring score, and some patients with rejection had a high score [170]. Further large-scale studies with more sophisticated measurements of immune monitoring methods are needed to achieve personalized immunosuppression.

Rejection diagnostic methods

Donor-derived cell-free DNA (dd-cfDNA) is an emerging noninvasive tool for diagnosis of rejection. The dd-cfDNA is detectable in both blood and urine of transplant recipients. After transplantation, dd-cfDNA rises to $>5 \%$ of total cfDNA and decreases sequentially to $<0.5 \%$ within 1 week. When a rejection event occurs,
dd-cfDNA could increase up to 5 -fold from the baseline value in the blood [171]. The dd-cfDNA is a potential candidate as a noninvasive tool for diagnosis of graft rejection, as the degree of dd-cfDNA elevation has been shown to be correlated with acute cellular rejection events, as determined by endomyocardial biopsy in early studies [172].

\section{Expanding the donor pool}

As the number of the donors is very small compared to patients requiring HT, there have been continuing efforts to expand the donor pool. To maximize the number of patients receiving HT, some transplantation centers now use extended criteria donor (ECD) hearts in high-risk recipients, and the outcomes seem to be acceptable. The general characteristics of ECD hearts are as follows: age $>50$ years, female donor, heart from patients with cardiovascular death, hypertension, diabetes, elevation of cardiac troponin, LV systolic dysfunction (LVEF < 50\%), and regional wall motion abnormalities. Moreover, the criteria for high-risk recipients are as follows: age $>65$ years, renal insufficiency, peripheral artery disease, or poorly controlled diabetes. The ECD program has had little impact on the outcome of transplanted patients and seems to accomplish the purpose of expanding the donor pool [173].

The concept of donation after circulatory death (DCD) was introduced as part of the efforts to expand the donor pool. To minimize the damage due to ischemic time in DCD organs, trials to utilize ex vivo perfusion systems were performed. The ex vivo heart perfusion system maintains the heart in a beating and metabolically active state by supplying warm, oxygenated, and nutrient-enriched donor blood. Recently, ex vivo perfusion systems have been reported to show non-inferiority with regard to outcome compared with standard cold storage methods, and further trials are currently underway [89].

\section{ACUTE HEART FAILURE}

AHF refers to rapid onset or worsening of symptoms and/or signs of HF. It is a life-threatening medical condition requiring urgent evaluation and treatment, typically leading to urgent hospital admission [1]. The 


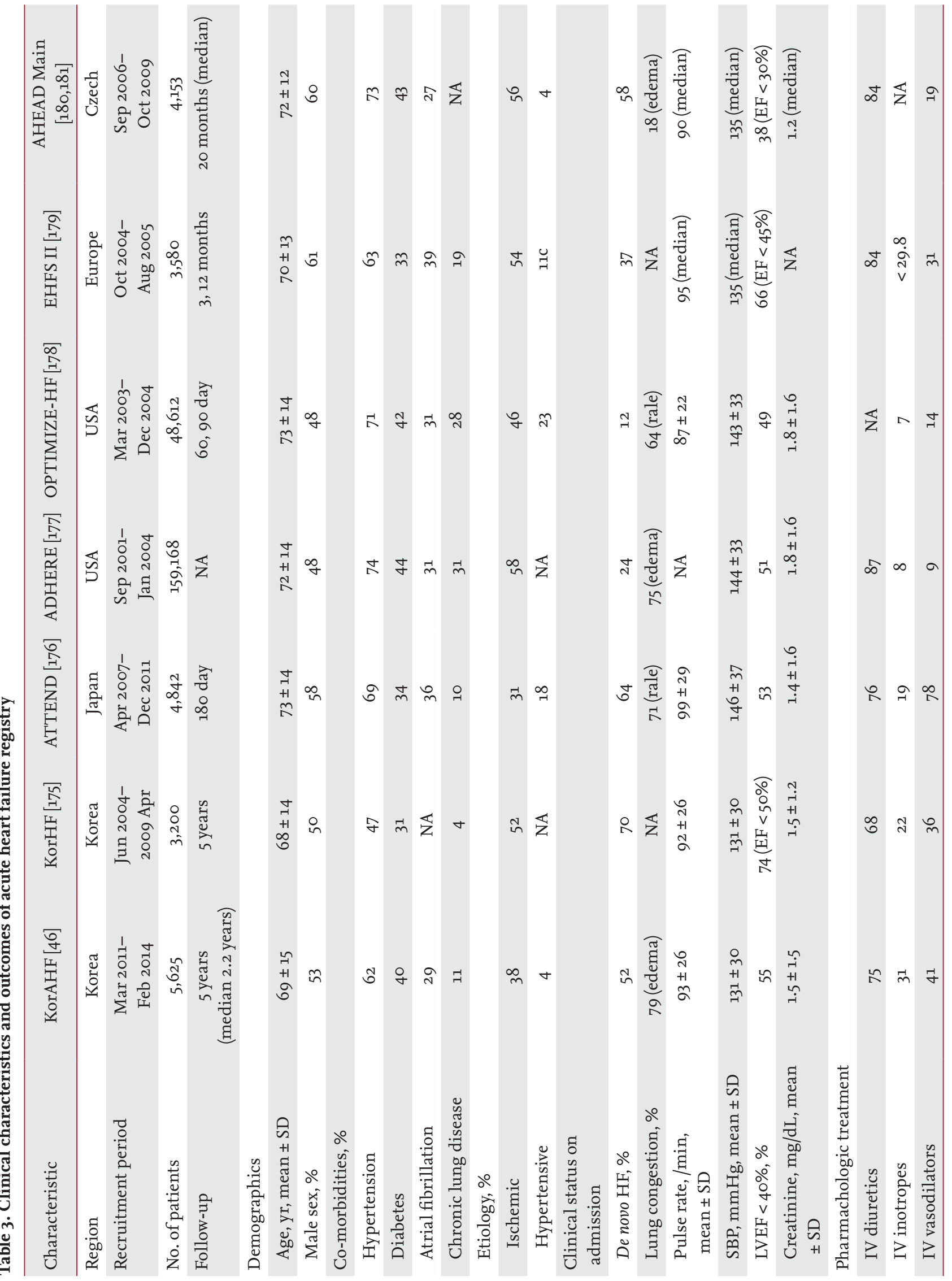




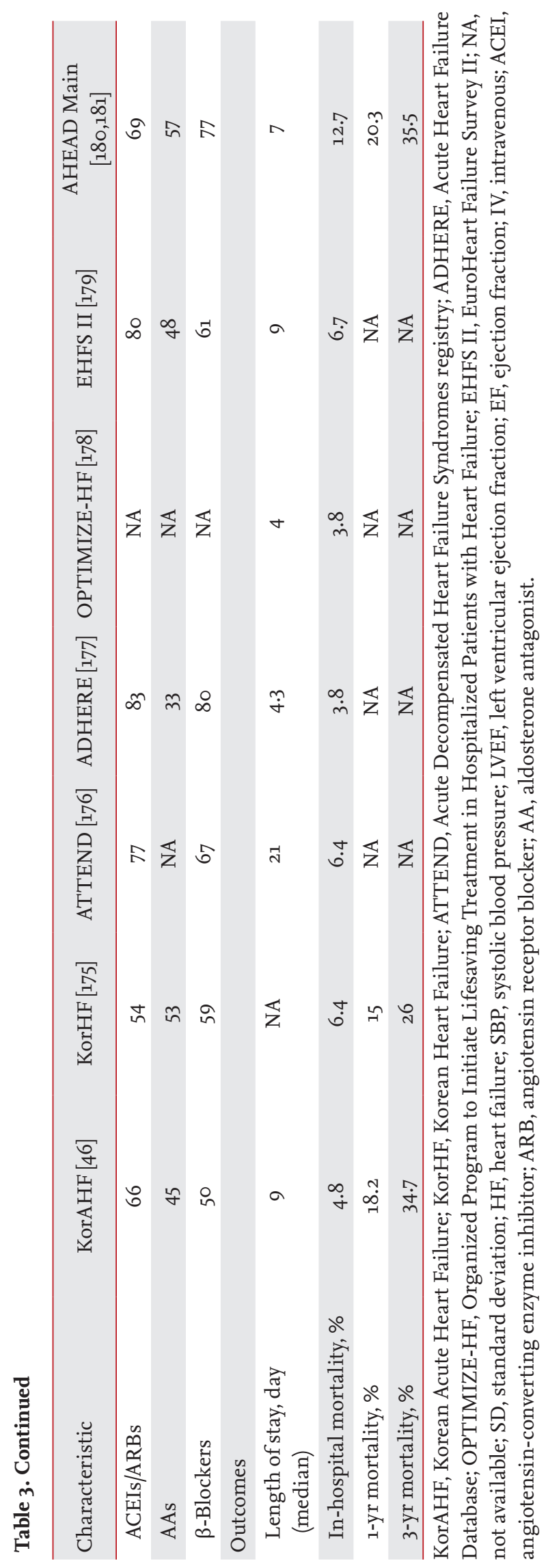

outcome of hospitalized HF patients in Korea has shown a modest improving trend over time, although treatment of AHF has not changed for several decades [3]. Clinical characteristics and outcomes of AHF registry according to different countries are summarized in Table 3 [46,174-181]. Many novel drugs have shown no clinical improvement [1]. This is because AHF syndrome is an event in the context of underlying HF, and not a disease entity per se [182]. Notably, the mid- or long-term outcome of AHF may not depend on treatment at the acute stage, but on the underlying disease status causing decompensation [46,183]. In addition, the classification of AHF is not clear [184-187]. Inadequate phenotyping is also responsible for the failure of treatments to improve outcomes in AHF. In this section, we focus on new treatment strategies and the attempt to reduce readmission to hospital (Table 4).

Diuretics are the mainstay of pharmacological treatment in AHF to improve symptoms [188]. Recently, the time-to-diuretics concept was proposed for AHF. A large prospective observational study showed a lower rate of in-hospital mortality in patients with door-to-diuretics time $<1$ hour [189]. In contrast, another observational study failed to show any associations between clinical outcomes and short door-to-diuretics time [190]. Newly developed intravenous vasodilators failed to improve outcomes in AHF. Nesiritide, recombinant BNP with a vasodilating effect, did not show improvement in dyspnea and in death or rehospitalization but showed a significantly higher rate of hypotension in the Acute Study of Clinical Effectiveness of Nesiritide in Decompensated Heart Failure (ASCEND HF) RCT [191]. Serelaxin, i.e., recombinant human relaxin-2, improved dyspnea and 180-day mortality rate in the RELAXin in acute heart failure (RELAX-AHF) randomized trial [192], but did not show consistent results in the subsequent RELAX-AHF-2 study (NCT01870778) [193]. Ularitide did not improve clinical outcomes in the Trial of Ularitide Efficacy and Safety in Acute Heart Failure (TRUE-AHF) trial [194]. The inodilator, levosimendan, was associated with reduction of short- and long-term mortality rates compared with placebo in LV dysfunction patients with acute MI [195]. However, there was no mortality benefit of levosimendan in comparison with dobutamine [196]. Recently, the PIONEER-HF study showed encouraging results in HFrEF patients who were hospitalized 
Table 4. Recent evidence regarding mortality in treatment of acute heart failure

\begin{tabular}{|c|c|c|c|c|c|c|c|}
\hline Topic & Study & Year & Author & No. & Intervention & Comparator & Finding \\
\hline \multirow[t]{3}{*}{ Diuretics } & $\begin{array}{l}\text { REALITY- } \\
\text { AHF }\end{array}$ & 2017 & $\begin{array}{l}\text { Matsue } \\
\text { et al. [189] }\end{array}$ & 1,291 & $\begin{array}{l}\text { Door to } \\
\text { diuretics time }\end{array}$ & $\begin{array}{l}\text { NA } \\
\text { (prospective } \\
\text { cohort) }\end{array}$ & $\begin{array}{l}\text { Early treatment with IV loop } \\
\text { diuretics (<6o min) was } \\
\text { associated with lower in- } \\
\text { hospital mortality. }\end{array}$ \\
\hline & KorAHF & 2018 & $\begin{array}{l}\text { Park et al. } \\
{[190]}\end{array}$ & 5,625 & $\begin{array}{l}\text { Door to } \\
\text { diuretics time }\end{array}$ & $\begin{array}{l}\text { NA } \\
\text { (prospective } \\
\text { cohort) }\end{array}$ & $\begin{array}{l}\text { Door to diuretics time was } \\
\text { not associated with clinical } \\
\text { outcome. }\end{array}$ \\
\hline & EVEREST & 2017 & $\begin{array}{l}\text { Konstam } \\
\text { et al. [99] }\end{array}$ & 4,133 & Tolvaptan & Placebo & $\begin{array}{l}\text { Tolvaptan did not show benefit } \\
\text { in long-term mortality and } \\
\text { composite of cardiovascular } \\
\text { death and HF hospitalization. }\end{array}$ \\
\hline \multirow[t]{4}{*}{ Vasodilators } & ASCEND-HF & 2011 & $\begin{array}{l}\text { O'Connor } \\
\text { et al. [191] }\end{array}$ & 7,141 & Nesiritide & Placebo & $\begin{array}{l}\text { Nesiritide was not associated } \\
\text { with change of HF } \\
\text { rehospitalization and death } \\
\text { within } 30 \text { days. }\end{array}$ \\
\hline & RELAX-AHF & 2013 & $\begin{array}{l}\text { Teerlink } \\
\text { et al. [192] }\end{array}$ & 1,161 & Serelaxin & Placebo & $\begin{array}{l}\text { Serelaxin was associated with } \\
\text { dyspnea relief and decrease in } \\
\text { 180-day mortality. }\end{array}$ \\
\hline & RELAX-AHF-2 & 2017 & $\begin{array}{l}\text { Abstract } \\
{[193]}\end{array}$ & 6,545 & Serelaxin & Placebo & $\begin{array}{l}\text { Serelaxin did not showed } \\
\text { significant difference in } \\
\text { 180-day all-cause and } \\
\text { cardiovascular mortality. }\end{array}$ \\
\hline & TRUE-AHF & 2017 & $\begin{array}{l}\text { Packer } \\
\text { et al. [194] }\end{array}$ & 2,157 & Ulraritide & Placebo & $\begin{array}{l}\text { Ularitide did not showed } \\
\text { significant difference in } \\
\text { cardiovascular death at } \\
\text { a median follow-up of } 15 \\
\text { months. }\end{array}$ \\
\hline \multirow[t]{2}{*}{ Inodilator } & RUSSLAN & 2002 & $\begin{array}{l}\text { Moiseyev } \\
\text { et al. [195] }\end{array}$ & 504 & Levosimendan & Placebo & $\begin{array}{l}\text { Levosimendan was associated } \\
\text { with reduction in 14- and } 180- \\
\text { day mortality in patients with } \\
\text { LV dysfunction due to AMI. }\end{array}$ \\
\hline & SURVIVE & 2007 & $\begin{array}{l}\text { Mebazaa } \\
\text { et al. [196] }\end{array}$ & 1,327 & Levosimendan & Dobutamine & $\begin{array}{l}\text { Levosimendan did not } \\
\text { significantly reduce all-cause } \\
\text { mortality at } 180 \text { days. }\end{array}$ \\
\hline
\end{tabular}

REALITY-AHF, Registry Focused on Very Early Presentation and Treatment in Emergency Department of Acute Heart Failure; NA, not available; IV, intravenous; KorAHF, Korean Acute Heart Failure; EVEREST, Efficacy of Vasopressin Antagonism in Heart Failure Outcome Study With Tolvaptan; HF, heart failure; ASCEND-HF, Acute Study of Clinical Effectiveness of Nesiritide in Decompensated Heart Failure; RELAX-AHF, Trial of RELAXin in Acute Heart Failure; TRUE-AHF, Ularitide Efficacy and Safety in Acute Heart Failure; RUSSLAN, Randomised stUdy on Safety and effectivenesS of Levosimendan in patients with left ventricular failure due to an Acute myocardial iNfarct; LV, left ventricle; AMI, acute myocardial infarction; SURVIVE, Survival of Patients With Acute Heart Failure in Need of Intravenous Inotropic Support.

for acute decompensated HF. The initiation of sacubitril-valsartan therapy led to a greater reduction of NT-proBNP concentration than enalapril therapy, with no significant difference in rate of adverse events, such as deteriorating renal function, hypotension, hyperka- lemia, and angioedema [197]. However, the role of ARNI in AHF should be verified in larger prospective study.

As outlined above, the treatment strategy for AHF has not changed markedly over the last several years. However, the rate of readmission after an AHF episode 
is consistently high, reaching $20 \%$ and $50 \%$ at 1 and 6 months after discharge, respectively [198]. To reduce the healthcare costs associated with AHF, the hospital readmission reduction program was introduced in the USA, which awarded a penalty to hospitals with high 30-day readmission rates. However, the results have been disappointing. The 30-day and 1-year readmission rates decreased, while the mortality rate tended to increase [199]. In addition, the quality of care and clinical outcome were similar between hospitals with high and low risk-adjusted 30-day HF readmission rates [200], and the mortality rate was lower in the higher hospital-level 30-day episode payment [201]. It is possible that some hospitals attempted to improve the index rather than the true outcome by adopting methods, such as increased admission period, delaying readmission after 30 days, etc., resulting in an unintended increase in mortality rate [202]. Remote monitoring mentioned in the previous section can be utilized for the early detection of deterioration and the prevention of readmission in AHF patients.

\section{DIGITAL HEALTHCARE IN HEART FAILURE}

Digital healthcare has received much attention recently. As the amounts of information from diverse sources, such as electronic medical records, wearable devices, and genomic data, are increasing rapidly, artificial intelligence and machine learning are essential to collect, manage, and apply these data appropriately [203]. Ahmad et al. [204] reported that machine learning could improve prognostic prediction and phenotyping with different treatment responses in a large cohort of $\mathrm{HF}$ patients. The use of artificial intelligence and clinical decision support systems is not suitable for clinical application. However, it may help physicians to make decisions by organizing large amounts of data and building delicate prognostic models in the near future.

\section{CONCLUSIONS}

HF is becoming an increasingly important disease entity with the aging of society. According to its increasing prevalence, many new drugs and devices have been studied to improve clinical outcome in terms of mortality and quality of life in HF patients. Although few studies showed encouraging results, researchers are attempting to find subgroups in whom certain medications or devices could be most effective, new methods for better diagnosis and prediction of prognosis in $\mathrm{HF}$ patients, and new tools for treating HF.

\section{Conflict of interest}

No potential conflict of interest relevant to this article was reported.

\section{Acknowledgments}

This study was supported by Basic Science Research Program through the National Research Foundation of Korea (NRF) funded by the Ministry of Science, ICT \& Future Planning (NRF-2018R1C1B6005448). The funders had no role in study design, data collection and analysis, decision to publish, or preparation of the manuscript.

The authors express sincere gratitude to all members of Korean Society of Heart Failure, which is the Korea's leading academic organization dedicated to the study of heart failure since 2003. For critical suggestions, discussion and manuscript review, we thank Sang Eun Lee, Sung-Ho Jung, Jae-Joong Kim (Asan Medical Center), Sang-Hyun Ihm (Bucheon St. Mary's Hospital), Jae Yeong Cho, Kye Hun Kim (Chonnam National University Hospital), Ju-Hee Lee, Kyung-Kuk Hwang, Myeong-Chan Cho (Chungbuk National University Hospital), Jae-Hyeong Park, Jin-Ok Jeong (Chungnam National University Hospital), Kyung-Jin Kim (Ewha Womans University Medical Center), Wook-Jin Chung, Mi-Seung Shin (Gachon University Gil Medical Center), Mi-Hyang Jung (Hallym University Chuncheon Sacred Heart Hospital), Sun Ki Lee, Suk-Won Choi, Seongwoo Han, Kyu-Hyung Ryu (Hallym University Dongtan Sacred Heart Hospital), Sang-Ho Jo (Hallym University Hallym Sacred Heart Hospital), Jae Hyuk Choi (Hallym University Hangang Sacred Heart Hospital), Dae-Gyun Park (Hallym University Kangdong Sacred Heart Hospital), Seonghoon Choi (Hallym University Kangnam Sacred Heart Hospital), In-Cheol Kim (Keimyung University Dongsan Medical Center), Mi-Na Kim, Jaemin Shim, Seong-Mi Park (Korea University Anam Hospital), Eung Ju Kim (Korea University Guro 
Hospital), Se Yong Jang, Dong Heon Yang, Shung Chull Chae (Kyungpook National University Hospital), Hyemoon Chung (Kyung Hee University Hospital), Jung Hyun Choi (Pusan National University Hospital), Darae Kim, Yang Hyun Cho, Sung-Ji Park, Jin-Oh Choi, EunSeok Jeon (Samsung Medical Center), Kyung-Hee Kim, Sang-Weon Park, Sook Jin Lee, Suk Keun Hong (Sejong General Hospital), Hyun-Jai Cho, Hae-Young Lee (Seoul National University Hospital), Jin Joo Park, Dong-Ju Choi (Seoul National University Bundang Hospital), Sang Hong Baek (Seoul St. Mary's Hospital), Eui-Young Choi (Yonsei University Gangnam Severance Hospital) Byung-Su Yoo (Yonsei University Wonju Severance Christian Hospital), Jaewon Oh, Yoo Jin Hong, HyeJeong Lee, Jae-Sun Uhm, Chi Young Shim, and SeokMin Kang (Yonsei University Severance Hospital).

\section{REFERENCES}

1. Ponikowski P, Voors AA, Anker SD, et al. 2016 ESC guidelines for the diagnosis and treatment of acute and chronic heart failure: the task force for the diagnosis and treatment of acute and chronic heart failure of the European Society of Cardiology (ESC) developed with the special contribution of the Heart Failure Association (HFA) of the ESC. Eur Heart J 2016;37:2129-2200.

2. Kim MS, Lee JH, Kim EJ, et al. Korean guidelines for diagnosis and management of chronic heart failure. Korean Circ J 2017;47:555-643.

3. Youn JC, Han S, Ryu KH. Temporal trends of hospitalized patients with heart failure in Korea. Korean Circ J 2017;47:16-24.

4. Rastogi A, Novak E, Platts AE, Mann DL. Epidemiology, pathophysiology and clinical outcomes for heart failure patients with a mid-range ejection fraction. Eur J Heart Fail 2017;19:1597-605.

5. Mosterd A, Hoes AW. Clinical epidemiology of heart failure. Heart 2007;93:1137-1146.

6. Owan TE, Hodge DO, Herges RM, Jacobsen SJ, Roger VL, Redfield MM. Trends in prevalence and outcome of heart failure with preserved ejection fraction. N Engl J Med 2006;355:251-259.

7. Lee JH, Lim NK, Cho MC, Park HY. Epidemiology of heart failure in Korea: present and future. Korean Circ J 2016;46:658-664.
8. Roberts E, Ludman AJ, Dworzynski K, et al. The diagnostic accuracy of the natriuretic peptides in heart failure: systematic review and diagnostic meta-analysis in the acute care setting. BMJ 2015;350:h910.

9. SPRINT Research Group, Wright JT Jr, Williamson JD, et al. A randomized trial of intensive versus standard blood-pressure control. N Engl J Med 2015;373:2103-2116.

10. Curtis JP, Sokol SI, Wang Y, et al. The association of left ventricular ejection fraction, mortality, and cause of death in stable outpatients with heart failure. J Am Coll Cardiol 2003;42:736-742.

11. Meta-analysis Global Group in Chronic Heart Failure (MAGGIC). The survival of patients with heart failure with preserved or reduced left ventricular ejection fraction: an individual patient data meta-analysis. Eur Heart J 2012;33:1750-1757.

12. Zakeri R, Cowie MR. Heart failure with preserved ejection fraction: controversies, challenges and future directions. Heart 2018;104:377-384.

13. Potter E, Marwick TH. Assessment of left ventricular function by echocardiography: the case for routinely adding global longitudinal strain to ejection fraction. JACC Cardiovasc Imaging 2018;11:260-274.

14. Park JJ, Park JB, Park JH, Cho GY. Global longitudinal strain to predict mortality in patients with acute heart failure. J Am Coll Cardiol 2018;71:1947-1957.

15. Ersboll M, Valeur N, Mogensen UM, et al. Prediction of all-cause mortality and heart failure admissions from global left ventricular longitudinal strain in patients with acute myocardial infarction and preserved left ventricular ejection fraction. J Am Coll Cardiol 2013;61:2365-2373.

16. Plana JC, Galderisi M, Barac A, et al. Expert consensus for multimodality imaging evaluation of adult patients during and after cancer therapy: a report from the American Society of Echocardiography and the European Association of Cardiovascular Imaging. J Am Soc Echocardiogr 2014;27:911-939.

17. Greyson CR. Pathophysiology of right ventricular failure. Crit Care Med 2008;36:S57-S65.

18. de Groote P. Right ventricular systolic function in heart failure: a long story but still the same question. Arch Cardiovasc Dis 2016;109:227-230.

19. Tadic M, Pieske-Kraigher E, Cuspidi C, et al. Right ventricular strain in heart failure: clinical perspective. Arch Cardiovasc Dis 2017;110:562-571.

20. Iacoviello M, Citarelli G, Antoncecchi V, et al. Right ven- 
tricular longitudinal strain measures independently predict chronic heart failure mortality. Echocardiography 2016;33:992-1000.

21. Park JH, Park JJ, Park JB, Cho GY. Prognostic value of biventricular strain in risk stratifying in patients with acute heart failure. J Am Heart Assoc 2018;7:eoo9331.

22. Farsalinos KE, Daraban AM, Unlu S, Thomas JD, Badano LP, Voigt JU. Head-to-head comparison of global longitudinal strain measurements among nine different vendors: the EACVI/ASE inter-vendor comparison study. J Am Soc Echocardiogr 2015;28:1171-1181.

23. Schelbert EB, Messroghli DR. State of the art: clinical applications of cardiac T1 mapping. Radiology 2016;278:658676.

24. Mascherbauer J, Marzluf BA, Tufaro C, et al. Cardiac magnetic resonance postcontrast $\mathrm{T} 1$ time is associated with outcome in patients with heart failure and preserved ejection fraction. Circ Cardiovasc Imaging 2013;6:10561065 .

25. Youn JC, Hong YJ, Lee HJ, et al. Contrast-enhanced T1 mapping-based extracellular volume fraction independently predicts clinical outcome in patients with non-ischemic dilated cardiomyopathy: a prospective cohort study. Eur Radiol 2017;27:3924-3933.

26. Puntmann VO, Voigt $T$, Chen $Z$, et al. Native T1 mapping in differentiation of normal myocardium from diffuse disease in hypertrophic and dilated cardiomyopathy. JACC Cardiovasc Imaging 2013;6:475-484.

27. Puntmann VO, Carr-White G, Jabbour A, et al. T1-mapping and outcome in nonischemic cardiomyopathy: allcause mortality and heart failure. JACC Cardiovasc Imaging 2016;9:40-50.

28. Lee HJ, Im DJ, Youn JC, et al. Myocardial extracellular volume fraction with dual-energy equilibrium contrast-enhanced cardiac CT in nonischemic cardiomyopathy: a prospective comparison with cardiac MR imaging. Radiology 2016;280:49-57.

29. Lee HJ, Im DJ, Youn JC, et al. Assessment of myocardial delayed enhancement with cardiac computed tomography in cardiomyopathies: a prospective comparison with delayed enhancement cardiac magnetic resonance imaging. Int J Cardiovasc Imaging 2017;33:577-584.

30. Chang S, Han K, Youn JC, et al. Utility of dual-energy CTbased monochromatic imaging in the assessment of myocardial delayed enhancement in patients with cardiomyopathy. Radiology 2018;287:442-451.
31. Ohta Y, Kitao S, Yunaga H, et al. Myocardial delayed enhancement CT for the evaluation of heart failure: comparison to MRI. Radiology 2018;288:682-691.

32. Vliegenthart R, Pelgrim GJ, Ebersberger U, Rowe GW, Oudkerk M, Schoepf UJ. Dual-energy CT of the heart. AJR Am J Roentgenol 2012;199:S54-S63.

33. Yancy CW, Januzzi JL Jr, Allen LA, et al. 2017 ACC expert consensus decision pathway for optimization of heart failure treatment: answers to 10 pivotal issues about heart failure with reduced ejection fraction: a report of the American College of Cardiology task force on expert consensus decision pathways. J Am Coll Cardiol 2018;71:201-230.

34. de Boer RA, Daniels LB, Maisel AS, Januzzi JL Jr. State of the art: newer biomarkers in heart failure. Eur J Heart Fail 2015;17:559-569.

35. Lassus J, Gayat E, Mueller C, et al. Incremental value of biomarkers to clinical variables for mortality prediction in acutely decompensated heart failure: the Multinational Observational Cohort on Acute Heart Failure (MOCA) study. Int J Cardiol 2013;168:2186-2194.

36. Breidthardt T, Balmelli C, Twerenbold R, et al. Heart failure therapy-induced early ST2 changes may offer longterm therapy guidance. J Card Fail 2013;19:821-828.

37. Bayes-Genis A, Zamora E, de Antonio M, et al. Soluble $\mathrm{ST} 2$ serum concentration and renal function in heart failure. J Card Fail 2013;19:768-775.

38. Kim MS, Jeong TD, Han SB, Min WK, Kim JJ. Role of soluble ST2 as a prognostic marker in patients with acute heart failure and renal insufficiency. J Korean Med Sci 2015;30:569-575.

39. Gehlken C, Suthahar N, Meijers WC, de Boer RA. Galectin-3 in heart failure: an update of the last 3 years. Heart Fail Clin 2018;14:75-92.

40. Braunwald E. Biomarkers in heart failure. N Engl J Med 2008;358:2148-2159.

41. Jackson CE, Haig C, Welsh P, et al. The incremental prognostic and clinical value of multiple novel biomarkers in heart failure. Eur J Heart Fail 2016;18:1491-1498.

42. Januzzi JL, Troughton R. Are serial BNP measurements useful in heart failure management? Serial natriuretic peptide measurements are useful in heart failure management. Circulation 2013;127:500-507.

43. Savarese G, Trimarco B, Dellegrottaglie S, et al. Natriuretic peptide-guided therapy in chronic heart failure: a meta-analysis of 2,686 patients in 12 randomized trials. PLoS 
One 2013;8:e58287.

44. Felker GM, Anstrom KJ, Adams KF, et al. Effect of natriuretic peptide-guided therapy on hospitalization or cardiovascular mortality in high-risk patients with heart failure and reduced ejection fraction: a randomized clinical trial. JAMA 2017;318:713-720.

45. Roth GA, Poole JE, Zaha R, Zhou W, Skinner J, Morden NE. Use of guideline-directed medications for heart failure before cardioverter-defibrillator implantation. J Am Coll Cardiol 2016;67:1062-1069.

46. Lee SE, Lee HY, Cho HJ, et al. Clinical characteristics and outcome of acute heart failure in Korea: results from the Korean Acute Heart Failure Registry (KorAHF). Korean Circ J 2017;47:341-353.

47. Biegstraaten M, Arngrimsson R, Barbey F, et al. Recommendations for initiation and cessation of enzyme replacement therapy in patients with Fabry disease: the European Fabry Working Group consensus document. Orphanet J Rare Dis 2015;10:36.

48. Judge DP. Use of genetics in the clinical evaluation of cardiomyopathy. JAMA 2009;302:2471-2476.

49. Skrzynia C, Berg JS, Willis MS, Jensen BC. Genetics and heart failure: a concise guide for the clinician. Curr Cardiol Rev 2015;11:10-17.

50. Hershberger RE, Givertz MM, Ho CY, et al. Genetic evaluation of cardiomyopathy: a Heart Failure Society of America Practice Guideline. J Card Fail 2018;24:281-302.

51. Maron BJ, Towbin JA, Thiene G, et al. Contemporary definitions and classification of the cardiomyopathies: an American Heart Association Scientific Statement from the Council on Clinical Cardiology, Heart Failure and Transplantation Committee; Quality of Care and Outcomes Research and Functional Genomics and Translational Biology Interdisciplinary Working Groups; and Council on Epidemiology and Prevention. Circulation 2006;113:1807-1816.

52. Elliott P, Andersson B, Arbustini E, et al. Classification of the cardiomyopathies: a position statement from the European Society Of Cardiology Working Group on Myocardial and Pericardial Diseases. Eur Heart J 2008;29:270276.

53. Arbustini E, Narula N, Tavazzi L, et al. The MOGE(S) classification of cardiomyopathy for clinicians. J Am Coll Cardiol 2014;64:304-318.

54. Cohn JN, Archibald DG, Ziesche S, et al. Effect of vasodilator therapy on mortality in chronic congestive heart failure. Results of a Veterans Administration Cooperative Study. N Engl J Med 1986;314:1547-1552.

55. Swedberg K, Komajda M, Bohm M, et al. Ivabradine and outcomes in chronic heart failure (SHIFT): a randomised placebo-controlled study. Lancet 2010;376:875-885.

56. McMurray JJ, Packer M, Desai AS, et al. Angiotensin-neprilysin inhibition versus enalapril in heart failure. N Engl J Med 2014;371:993-1004.

57. CONSENSUS Trial Study Group. Effects of enalapril on mortality in severe congestive heart failure. Results of the Cooperative North Scandinavian Enalapril Survival Study (CONSENSUS). N Engl J Med 1987;316:1429-1435.

58. SOLVD Investigators, Yusuf S, Pitt B, Davis CE, Hood WB, Cohn JN. Effect of enalapril on survival in patients with reduced left ventricular ejection fractions and congestive heart failure. N Engl J Med 1991;325:293-302.

59. Packer M, Bristow MR, Cohn JN, et al. The effect of carvedilol on morbidity and mortality in patients with chronic heart failure. U.S. Carvedilol Heart Failure Study Group. N Engl J Med 1996;334:1349-1355.

6o. Pitt B, Zannad F, Remme WJ, et al. The effect of spironolactone on morbidity and mortality in patients with severe heart failure. Randomized Aldactone Evaluation Study Investigators. N Engl J Med 1999;341:709-717.

61. Packer M, Poole-Wilson PA, Armstrong PW, et al. Comparative effects of low and high doses of the angiotensin-converting enzyme inhibitor, lisinopril, on morbidity and mortality in chronic heart failure. ATLAS Study Group. Circulation 1999;100:2312-2318.

62. Granger CB, McMurray JJ, Yusuf S, et al. Effects of candesartan in patients with chronic heart failure and reduced left-ventricular systolic function intolerant to angiotensin-converting-enzyme inhibitors: the CHARM-Alternative trial. Lancet 2003;362:772-776.

63. Zinman B, Wanner C, Lachin JM, et al. Empagliflozin, cardiovascular outcomes, and mortality in type 2 diabetes. N Engl J Med 2015;373:2117-2128.

64. Marso SP, Daniels GH, Brown-Frandsen K, et al. Liraglutide and cardiovascular outcomes in type 2 diabetes. $\mathrm{N}$ Engl J Med 2016;375:311-322.

65. Neal B, Perkovic V, Mahaffey KW, et al. Canagliflozin and cardiovascular and renal events in type 2 diabetes. $\mathrm{N}$ Engl J Med 2017;377:644-657.

66. Ridker PM, Everett BM, Thuren T, et al. Antiinflammatory therapy with canakinumab for atherosclerotic disease. N Engl J Med 2017;377:1119-1131. 
67. Wiviott SD, Raz I, Bonaca MP, et al. Dapagliflozin and cardiovascular outcomes in type 2 diabetes. $\mathrm{N}$ Engl J Med 2018 Nov 10 [Epub]. https://doi.org/10.1056/NEJMoa1812389.

68. Maurer MS, Schwartz JH, Gundapaneni B, et al. Tafamidis treatment for patients with transthyretin amyloid cardiomyopathy. N Engl J Med 2018;379:1007-1016.

69. Moss AJ, Hall WJ, Cannom DS, et al. Improved survival with an implanted defibrillator in patients with coronary disease at high risk for ventricular arrhythmia. Multicenter Automatic Defibrillator Implantation Trial Investigators. N Engl J Med 1996;335:1933-1940.

70. Buxton AE, Lee KL, Fisher JD, Josephson ME, Prystowsky EN, Hafley G. A randomized study of the prevention of sudden death in patients with coronary artery disease. Multicenter Unsustained Tachycardia Trial Investigators. N Engl J Med 1999;341:1882-1890.

71. Moss AJ, Zareba W, Hall WJ, et al. Prophylactic implantation of a defibrillator in patients with myocardial infarction and reduced ejection fraction. N Engl J Med 2002;346:877-883.

72. Kadish A, Dyer A, Daubert JP, et al. Prophylactic defibrillator implantation in patients with nonischemic dilated cardiomyopathy. N Engl J Med 2004;350:2151-2158.

73. Hohnloser SH, Kuck KH, Dorian P, et al. Prophylactic use of an implantable cardioverter-defibrillator after acute myocardial infarction. N Engl J Med 2004;351:2481-2488.

74. Bardy GH, Lee KL, Mark DB, et al. Amiodarone or an implantable cardioverter-defibrillator for congestive heart failure. N Engl J Med 2005;352:225-237.

75. Kober L, Thune JJ, Nielsen JC, et al. Defibrillator implantation in patients with nonischemic systolic heart failure. N Engl J Med 2016;375:1221-1230.

76. Olgin JE, Pletcher MJ, Vittinghoff E, et al. Wearable cardioverter-defibrillator after myocardial infarction. N Engl J Med 2018;379:1205-1215.

77. Bristow MR, Saxon LA, Boehmer J, et al. Cardiac-resynchronization therapy with or without an implantable defibrillator in advanced chronic heart failure. N Engl J Med 2004;350:2140-2150.

78. Cleland JG, Daubert JC, Erdmann E, et al. The effect of cardiac resynchronization on morbidity and mortality in heart failure. N Engl J Med 2005;352:1539-1549.

79. Linde C, Abraham WT, Gold MR, et al. Randomized trial of cardiac resynchronization in mildly symptomatic heart failure patients and in asymptomatic patients with left ventricular dysfunction and previous heart failure symptoms. J Am Coll Cardiol 2008;52:1834-1843.

8o. Moss AJ, Hall WJ, Cannom DS, et al. Cardiac-resynchronization therapy for the prevention of heart-failure events. N Engl J Med 2009;361:1329-1338.

81. Tang AS, Wells GA, Talajic M, et al. Cardiac-resynchronization therapy for mild-to-moderate heart failure. N Engl J Med 2010;363:2385-2395.

82. Rose EA, Gelijns AC, Moskowitz AJ, et al. Long-term use of a left ventricular assist device for end-stage heart failure. N Engl J Med 2001;345:1435-1443.

83. Miller LW, Pagani FD, Russell SD, et al. Use of a continuous-flow device in patients awaiting heart transplantation. N Engl J Med 2007;357:885-896.

84. Slaughter MS, Rogers JG, Milano CA, et al. Advanced heart failure treated with continuous-flow left ventricular assist device. N Engl J Med 2009;361:2241-2251.

85. Rogers JG, Pagani FD, Tatooles AJ, et al. Intrapericardial left ventricular assist device for advanced heart failure. $\mathrm{N}$ Engl J Med 2017;376:451-46o.

86. Mehra MR, Naka Y, Uriel N, et al. A fully magnetically levitated circulatory pump for advanced heart failure. $\mathrm{N}$ Engl J Med 2017;376:440-450.

87. Velazquez EJ, Lee KL, Jones RH, et al. Coronary-artery bypass surgery in patients with ischemic cardiomyopathy. N Engl J Med 2016;374:1511-1520.

88. Andreassen AK, Andersson B, Gustafsson F, et al. Everolimus initiation and early calcineurin inhibitor withdrawal in heart transplant recipients: a randomized trial. Am J Transplant 2014;14:1828-1838.

89. Ardehali A, Esmailian F, Deng M, et al. Ex-vivo perfusion of donor hearts for human heart transplantation (PROCEED II): a prospective, open-label, multicentre, randomised non-inferiority trial. Lancet 2015;385:2577-2584.

90. Ferrari R, Balla C, Fucili A. Heart failure: an historical perspective. Eur Heart J Suppl 2016;18(Suppl G):G3-G1O.

91. Flather MD, Yusuf S, Kober L, et al. Long-term ACE-inhibitor therapy in patients with heart failure or left-ventricular dysfunction: a systematic overview of data from individual patients. ACE-Inhibitor Myocardial Infarction Collaborative Group. Lancet 2000;355:1575-1581.

92. Bristow MR, Gilbert EM, Abraham WT, et al. Carvedilol produces dose-related improvements in left ventricular function and survival in subjects with chronic heart failure. MOCHA Investigators. Circulation 1996;94:28072816 . 
93. Heidenreich PA, Lee TT, Massie BM. Effect of beta-blockade on mortality in patients with heart failure: a meta-analysis of randomized clinical trials. J Am Coll Cardiol 1997;30:27-34.

94. Choi KH, Lee GY, Choi JO, et al. The mortality benefit of carvedilol versus bisoprolol in patients with heart failure with reduced ejection fraction. Korean J Intern Med 2018 Oct 16 [Epub]. https://doi.org/10.3904/kjim.2018.oo9.

95. Pitt B, Pedro Ferreira J, Zannad F. Mineralocorticoid receptor antagonists in patients with heart failure: current experience and future perspectives. Eur Heart J Cardiovasc Pharmacother 2017;3:48-57.

96. McMurray JJ, Ostergren J, Swedberg K, et al. Effects of candesartan in patients with chronic heart failure and reduced left-ventricular systolic function taking angiotensin-converting-enzyme inhibitors: the CHARM-Added trial. Lancet 2003;362:767-771.

97. Park GH, Lee CM, Song JW, et al. Comparison of tolvaptan treatment between patients with the SIADH and congestive heart failure: a single-center experience. Korean J Intern Med 2018;33:561-567.

98. Felker GM, Mentz RJ, Adams KF, et al. Tolvaptan in patients hospitalized with acute heart failure: rationale and design of the TACTICS and the SECRET of CHF trials. Circ Heart Fail 2015;8:997-1005.

99. Konstam MA, Kiernan M, Chandler A, et al. Short-term effects of tolvaptan in patients with acute heart failure and volume overload. J Am Coll Cardiol 2017;69:14091419.

100. Berliner D, Bauersachs J. Current drug therapy in chronic heart failure: the new guidelines of the European Society of Cardiology (ESC). Korean Circ J 2017;47:543-554.

101. Lytvyn Y, Bjornstad P, Udell JA, Lovshin JA, Cherney DZI. Sodium glucose cotransporter-2 inhibition in heart failure: potential mechanisms, clinical applications, and summary of clinical trials. Circulation 2017;136:1643-1658.

102. Ahmed HM, Khraishah H, Cho L. Cardioprotective anti-hyperglycaemic medications: a review of clinical trials. Eur Heart J 2018;39:2368-2375.

103. Verma S, Rawat S, Ho KL, et al. Empagliflozin increases cardiac energy production in diabetes: novel translational insights into the heart failure benefits of SGLT2 inhibitors. JACC Basic Transl Sci 2018;3:575-587.

104. Zelniker TA, Braunwald E. Cardiac and renal effects of sodium-glucose co-transporter 2 inhibitors in diabetes: JACC state-of-the-art review. J Am Coll Cardiol 2018;
72:1845-1855.

105. Cavender MA, Norhammar A, Birkeland KI, et al. SGLT-2 inhibitors and cardiovascular risk: an analysis of CVD-REAL. J Am Coll Cardiol 2018;71:2497-2506.

106. Kosiborod M, Lam CSP, Kohsaka S, et al. Cardiovascular events associated with SGLT-2 inhibitors versus other glucose-lowering drugs: the CVD-REAL 2 study. J Am Coll Cardiol 2018;71:2628-2639.

107. Byrne NJ, Parajuli N, Levasseur JL, et al. Empagliflozin prevents worsening of cardiac function in an experimental model of pressure overload-induced heart failure. JACC Basic Transl Sci 2017;2:347-354.

108. Custodio JS Jr, Duraes AR, Abreu M, Albuquerque Rocha $\mathrm{N}$, Roever L. SGLT2 inhibition and heart failure-current concepts. Heart Fail Rev 2018;23:409-418.

109. Varian K, Tang WHW. Therapeutic strategies targeting inherited cardiomyopathies. Curr Heart Fail Rep 2017; 14:321-330.

110. Jacoby D, Lester S, Owens A, et al. Reduction in left ventricular outflow tract gradient with mavacamten (Myk461) in symptomatic obstructive hypertrophic cardiomyopathy patients (PIONEER-HCM). J Am Coll Cardiol 2018;71(11 Suppl):A644.

111. Teerlink JR, Felker GM, McMurray JJV, et al. Acute treatment with omecamtiv mecarbil to increase contractility in acute heart failure: the ATOMIC-AHF study. J Am Coll Cardiol 2016;67:1444-1455.

112. Teerlink JR, Felker GM, McMurray JJ, et al. Chronic oral study of myosin activation to increase contractility in heart failure (COSMIC-HF): a phase 2, pharmacokinetic, randomised, placebo-controlled trial. Lancet 2016;388: 2895-2903.

113. Kaplinsky E, Mallarkey G. Cardiac myosin activators for heart failure therapy: focus on omecamtiv mecarbil. Drugs Context 2018;7:212518.

114. Bartekova M, Radosinska J, Jelemensky M, Dhalla NS. Role of cytokines and inflammation in heart function during health and disease. Heart Fail Rev 2018;23:733-758.

115. Van Tassell BW, Canada J, Carbone S, et al. Interleukin-1 blockade in recently decompensated systolic heart failure: results from REDHART (Recently Decompensated Heart Failure Anakinra Response Trial). Circ Heart Fail 2017;10:e004373.

116. Van Tassell BW, Buckley LF, Carbone S, et al. Interleukin-1 blockade in heart failure with preserved ejection fraction: rationale and design of the Diastolic Heart Failure Anak- 
inra Response Trial 2 (D-HART2). Clin Cardiol 2017;40: 626-632.

117. Van Tassell BW, Lipinski MJ, Appleton D, et al. Rationale and design of the Virginia Commonwealth University-Anakinra Remodeling Trial-3 (VCU-ART3): a randomized, placebo-controlled, double-blinded, multicenter study. Clin Cardiol 2018;41:1004-1008.

118. Gabisonia K, Recchia FA. Gene therapy for heart failure: new perspectives. Curr Heart Fail Rep 2018;15:340-349.

119. Greenberg B, Butler J, Felker GM, et al. Calcium upregulation by percutaneous administration of gene therapy in patients with cardiac disease (CUPID 2): a randomised, multinational, double-blind, placebo-controlled, phase 2b trial. Lancet 2016;387:1178-1186.

120. Hulot JS, Ishikawa K, Hajjar RJ. Gene therapy for the treatment of heart failure: promise postponed. Eur Heart J 2016;37:1651-1658.

121. Poglajen G, Vrtovec B. Stem cell therapy for chronic heart failure. Curr Opin Cardiol 2015;30:301-310.

122. Tompkins BA, Rieger AC, Florea V, et al. Comparison of mesenchymal stem cell efficacy in ischemic versus nonischemic dilated cardiomyopathy. J Am Heart Assoc 2018;7:e008460.

123. Park M, Yoon YS. Cardiac regeneration with human pluripotent stem cell-derived cardiomyocytes. Korean Circ J 2018;48:974-988.

124. Park $\mathrm{KH}$, Lee $\mathrm{CH}$, Jung BC, et al. Effectiveness of implantable cardioverter-defibrillator therapy for heart failure patients according to ischemic or non-ischemic etiology in Korea. Korean Circ J 2017;47:72-81.

125. Writing Committee members, Yancy CW, Jessup M, et al. 2013 ACCF/AHA guideline for the management of heart failure: a report of the American College of Cardiology Foundation/American Heart Association Task Force on practice guidelines. Circulation 2013;128:e240-e327.

126. Al-Khatib SM, Stevenson WG, Ackerman MJ, et al. 2017 AHA/ACC/HRS guideline for management of patients with ventricular arrhythmias and the prevention of sudden cardiac death: executive summary: a report of the American College of Cardiology/American Heart Association Task Force on Clinical Practice Guidelines and the Heart Rhythm Society. J Am Coll Cardiol 2018;72:16771749 .

127. Normand C, Linde C, Singh J, Dickstein K. Indications for cardiac resynchronization therapy: a comparison of the major international guidelines. JACC Heart Fail
2018;6:308-316.

128. Leyva F, Foley PW, Chalil S, et al. Cardiac resynchronization therapy guided by late gadolinium-enhancement cardiovascular magnetic resonance. J Cardiovasc Magn Reson 2011;13:29.

129. Khan FZ, Virdee MS, Palmer CR, et al. Targeted left ventricular lead placement to guide cardiac resynchronization therapy: the TARGET study: a randomized, controlled trial. J Am Coll Cardiol 2012;59:1509-1518.

130. Sommer A, Kronborg MB, Norgaard BL, et al. Multimodality imaging-guided left ventricular lead placement in cardiac resynchronization therapy: a randomized controlled trial. Eur J Heart Fail 2016;18:1365-1374.

131. Batul SA, Gopinathannair R. Atrial fibrillation in heart failure: a therapeutic challenge of our times. Korean Circ J 2017;47:644-662.

132. Marrouche NF, Brachmann J, Andresen D, et al. Catheter ablation for atrial fibrillation with heart failure. $\mathrm{N}$ Engl J Med 2018;378:417-427.

133. Di Biase L, Mohanty P, Mohanty S, et al. Ablation versus amiodarone for treatment of persistent atrial fibrillation in patients with congestive heart failure and an implanted device: results from the AATAC multicenter randomized trial. Circulation 2016;133:1637-1644.

134. Tofield A. The CABANA trial: a first glance at an important study. Eur Heart J 2018;39:2767-2768.

135. Brignole M, Pokushalov E, Pentimalli F, et al. A randomized controlled trial of atrioventricular junction ablation and cardiac resynchronization therapy in patients with permanent atrial fibrillation and narrow QRS. Eur Heart J 2018;39:3999-4008.

136. Abraham WT, Adamson PB, Bourge RC, et al. Wireless pulmonary artery haemodynamic monitoring in chronic heart failure: a randomised controlled trial. Lancet 2011;377:658-666.

137. Givertz MM, Stevenson LW, Costanzo MR, et al. Pulmonary artery pressure-guided management of patients with heart failure and reduced ejection fraction. J Am Coll Cardiol 2017;70:1875-1886.

138. Hindricks G, Taborsky M, Glikson M, et al. Implant-based multiparameter telemonitoring of patients with heart failure (IN-TIME): a randomised controlled trial. Lancet 2014;384:583-590.

139. Crossley GH, Boyle A, Vitense H, Chang Y, Mead RH; CONNECT Investigators. The CONNECT (Clinical Evaluation of Remote Notification to Reduce Time to Clinical 
Decision) trial: the value of wireless remote monitoring with automatic clinician alerts. J Am Coll Cardiol 2011;57:1181-1189.

140. Parthiban N, Esterman A, Mahajan R, et al. Remote monitoring of implantable cardioverter-defibrillators: a systematic review and meta-analysis of clinical outcomes. J Am Coll Cardiol 2015;65:2591-2600.

141. Whellan DJ, Ousdigian KT, Al-Khatib SM, et al. Combined heart failure device diagnostics identify patients at higher risk of subsequent heart failure hospitalizations: results from PARTNERS HF (Program to Access and Review Trending Information and Evaluate Correlation to Symptoms in Patients With Heart Failure) study. J Am Coll Cardiol 2010;55:1803-1810.

142. Bohm M, Drexler H, Oswald H, et al. Fluid status telemedicine alerts for heart failure: a randomized controlled trial. Eur Heart J 2016;37:3154-3163.

143. Boehmer JP, Hariharan R, Devecchi FG, et al. A multisensor algorithm predicts heart failure events in patients with implanted devices: results from the MultiSENSE study. JACC Heart Fail 2017;5:216-225.

144. Goliasch G, Bartko PE, Pavo N, et al. Refining the prognostic impact of functional mitral regurgitation in chronic heart failure. Eur Heart J 2018;39:39-46.

145. Michler RE, Smith PK, Parides MK, et al. Two-year outcomes of surgical treatment of moderate ischemic mitral regurgitation. N Engl J Med 2016;374:1932-1941.

146. Nishimura RA, Otto CM, Bonow RO, et al. 2014 AHA/ACC guideline for the management of patients with valvular heart disease: executive summary: a report of the American College of Cardiology/American Heart Association Task Force on Practice Guidelines. J Am Coll Cardiol 2014;63:2438-2488.

147. Feldman T, Cilingiroglu M. Percutaneous leaflet repair and annuloplasty for mitral regurgitation. J Am Coll Cardiol 2011;57:529-537.

148. Obadia JF, Messika-Zeitoun D, Leurent G, et al. Percutaneous repair or medical treatment for secondary mitral regurgitation. N Engl J Med 2018;379:2297-2306.

149. Stone GW, Lindenfeld J, Abraham WT, et al. Transcatheter mitral-valve repair in patients with heart failure. $\mathrm{N}$ Engl J Med 2018;379:2307-2318.

150. Messika-Zeitoun D, Nickenig G, Latib A, et al. Transcatheter mitral valve repair for functional mitral regurgitation using the cardioband system: 1 year outcomes. Eur Heart J 2018 Aug 16 [Epub]. https://doi.org/10.1093/eurheartj/ ehy424.

151. De Backer O, Piazza N, Banai S, et al. Percutaneous transcatheter mitral valve replacement: an overview of devices in preclinical and early clinical evaluation. Circ Cardiovasc Interv 2014;7:400-409.

152. Regueiro A, Granada JF, Dagenais F, Rodes-Cabau J. Transcatheter mitral valve replacement: insights from early clinical experience and future challenges. J Am Coll Cardiol 2017;69:2175-2192.

153. Feldman T, Mauri L, Kahwash R, et al. Transcatheter interatrial shunt device for the treatment of heart failure with preserved ejection fraction (REDUCE LAP-HF I [reduce elevated left atrial pressure in patients with heart failure]): a phase 2, randomized, sham-controlled trial. Circulation 2018;137:364-375.

154. Shah SJ, Feldman T, Ricciardi MJ, et al. One-year safety and clinical outcomes of a transcatheter interatrial shunt device for the treatment of heart failure with preserved ejection fraction in the reduce elevated left atrial pressure in patients with heart failure (REDUCE LAP-HF I) trial: a randomized clinical trial. JAMA Cardiol 2018;3:968-977.

155. Bohm M, Ewen S, Mahfoud F. Renal denervation for chronic heart failure: background and pathophysiological rationale. Korean Circ J 2017;47:9-15.

156. Zannad F, De Ferrari GM, Tuinenburg AE, et al. Chronic vagal stimulation for the treatment of low ejection fraction heart failure: results of the NEural Cardiac TherApy foR Heart Failure (NECTAR-HF) randomized controlled trial. Eur Heart J 2015;36:425-433.

157. De Ferrari GM, Stolen C, Tuinenburg AE, et al. Long-term vagal stimulation for heart failure: eighteen month results from the NEural Cardiac TherApy foR Heart Failure (NECTAR-HF) trial. Int J Cardiol 2017;244:229-234.

158. Gold MR, Van Veldhuisen DJ, Hauptman PJ, et al. Vagus nerve stimulation for the treatment of heart failure: the INOVATE-HF trial. J Am Coll Cardiol 2016;68:149-158.

159. Bhatt DL, Kandzari DE, O'Neill WW, et al. A controlled trial of renal denervation for resistant hypertension. $\mathrm{N}$ Engl J Med 2014;370:1393-1401.

160. Coppolino G, Pisano A, Rivoli L, Bolignano D. Renal denervation for resistant hypertension. Cochrane Database Syst Rev 2017;2:CDo11499.

161. Townsend RR, Mahfoud F, Kandzari DE, et al. Catheter-based renal denervation in patients with uncontrolled hypertension in the absence of antihypertensive medications (SPYRAL HTN-OFF MED): a randomised, sham-con- 
trolled, proof-of-concept trial. Lancet 2017;390:2160-2170.

162. Teuteberg JJ, Slaughter MS, Rogers JG, et al. The HVAD left ventricular assist device: risk factors for neurological events and risk mitigation strategies. JACC Heart Fail 2015;3:818-828.

163. Strueber M, Larbalestier R, Jansz P, et al. Results of the post-market registry to evaluate the HeartWare left ventricular assist system (ReVOLVE). J Heart Lung Transplant 2014;33:486-491.

164. Chatterjee A, Feldmann C, Dogan G, et al. Clinical overview of the HVAD: a centrifugal continuous-flow ventricular assist device with magnetic and hydrodynamic bearings including lateral implantation strategies. J Thorac Dis 2018;10:S1785-S1789.

165. Mehra MR, Goldstein DJ, Uriel N, et al. Two-year outcomes with a magnetically levitated cardiac pump in heart failure. N Engl J Med 2018;378:1386-1395.

166. Cohn WE, Timms DL, Frazier OH. Total artificial hearts: past, present, and future. Nat Rev Cardiol 2015;12:609-617.

167. Wells D, Villa CR, Simon Morales DL. The 50/50 cc total artificial heart trial: extending the benefits of the total artificial heart to underserved populations. Semin Thorac Cardiovasc Surg Pediatr Card Surg Annu 2017;20:16-19.

168. Lee HY, Jeon ES, Kang SM, Kim JJ. Initial report of the Korean Organ Transplant Registry (KOTRY): heart transplantation. Korean Circ J 2017;47:868-876.

169. Kittleson MM, Kobashigawa JA. Long-term care of the heart transplant recipient. Curr Opin Organ Transplant 2014;19:515-524.

170. Kobashigawa JA, Kiyosaki KK, Patel JK, et al. Benefit of immune monitoring in heart transplant patients using ATP production in activated lymphocytes. J Heart Lung Transplant 2010;29:504-508.

171. Kim IC, Youn JC, Kobashigawa JA. The past, present and future of heart transplantation. Korean Circ J 2018;48:565590.

172. Crespo-Leiro MG, Stypmann J, Schulz U, et al. Clinical usefulness of gene-expression profile to rule out acute rejection after heart transplantation: CARGO II. Eur Heart J 2016;37:2591-2601.

173. Zaroff JG, Rosengard BR, Armstrong WF, et al. Consensus conference report: maximizing use of organs recovered from the cadaver donor: cardiac recommendations, March 28-29, 2001, Crystal City, VA. Circulation 2002;106:836-841.

174. Lee SE, Cho HJ, Lee HY, et al. A multicentre cohort study of acute heart failure syndromes in Korea: rationale, de- sign, and interim observations of the Korean Acute Heart Failure (KorAHF) registry. Eur J Heart Fail 2014;16:700708.

175. Choi DJ, Han S, Jeon ES, et al. Characteristics, outcomes and predictors of long-term mortality for patients hospitalized for acute heart failure: a report from the Korean Heart Failure Registry. Korean Circ J 2011;41:363-371.

176. Sato N, Kajimoto K, Keida T, et al. Clinical features and outcome in hospitalized heart failure in Japan (from the ATTEND registry). Circ J 2013;77:944-951.

177. Fonarow GC, Heywood JT, Heidenreich PA, Lopatin M, Yancy CW; ADHERE Scientific Advisory Committee and Investigators. Temporal trends in clinical characteristics, treatments, and outcomes for heart failure hospitalizations, 2002 to 2004: findings from Acute Decompensated Heart Failure National Registry (ADHERE). Am Heart J 2007;153:1021-1028.

178. Abraham WT, Fonarow GC, Albert NM, et al. Predictors of in-hospital mortality in patients hospitalized for heart failure: insights from the organized program to initiate lifesaving treatment in hospitalized patients with heart failure (OPTIMIZE-HF). J Am Coll Cardiol 2008;52:347356.

179. Nieminen MS, Brutsaert D, Dickstein K, et al. EuroHeart Failure Survey II (EHFS II): a survey on hospitalized acute heart failure patients: description of population. Eur Heart J 2006;27:2725-2736.

180. Spinar J, Parenica J, Vitovec J, et al. Baseline characteristics and hospital mortality in the Acute Heart Failure Database (AHEAD) main registry. Crit Care 2011;15:R291.

181. Parenica J, Spinar J, Vitovec J, et al. Long-term survival following acute heart failure: the Acute Heart Failure Database Main registry (AHEAD main). Eur J Intern Med 2013;24:151-160.

182. Packer M. Acute heart failure is an event rather than a disease: plea for a radical change in thinking and in therapeutic drug development. JACC Heart Fail 2018;6:73-75.

183. Martens P, Mullens W. How to tackle congestion in acute heart failure. Korean J Intern Med 2018;33:462-473.

184. Filippatos G, Zannad F. An introduction to acute heart failure syndromes: definition and classification. Heart Fail Rev 2007;12:87-90.

185. Nieminen MS, Bohm M, Cowie MR, et al. Executive summary of the guidelines on the diagnosis and treatment of acute heart failure: the Task Force on Acute Heart Failure of the European Society of Cardiology. Eur Heart J 
2005;26:384-416.

186. Gheorghiade M, Zannad F, Sopko G, et al. Acute heart failure syndromes: current state and framework for future research. Circulation 2005;112:3958-3968.

187. Nohria A, Tsang SW, Fang JC, et al. Clinical assessment identifies hemodynamic profiles that predict outcomes in patients admitted with heart failure. J Am Coll Cardiol 2003;41:1797-1804.

188. Cerlinskaite K, Javanainen T, Cinotti R, Mebazaa A; Global Research on Acute Conditions Team (GREAT) Network. Acute heart failure management. Korean Circ J 2018; 48:463-480.

189. Matsue Y, Damman K, Voors AA, et al. Time-to-furosemide treatment and mortality in patients hospitalized with acute heart failure. J Am Coll Cardiol 2017;69:30423051.

190. Park JJ, Kim SH, Oh IY, et al. The effect of door-to-diuretic time on clinical outcomes in patients with acute heart failure. JACC Heart Fail 2018;6:286-294.

191. O'Connor CM, Starling RC, Hernandez AF, et al. Effect of nesiritide in patients with acute decompensated heart failure. N Engl J Med 2011;365:32-43.

192. Teerlink JR, Cotter G, Davison BA, et al. Serelaxin, recombinant human relaxin-2, for treatment of acute heart failure (RELAX-AHF): a randomised, placebo-controlled trial. Lancet 2013;381:29-39.

193. ClinicalTrials.gov. Efficacy, safety and tolerability of serelaxin when added to standard therapy in AHF (RELAX-AHF-2) [Internet]. Bethesda (MD): U.S. National Library of Medicine, 2013 [cited 2018 Dec 10]. Available from: https://clinicaltrials.gov/ct2/show/results/NCT01870778?term=relax-ahf-2\&rank=1.

194. Packer M, O'Connor C, McMurray JJV, et al. Effect of ularitide on cardiovascular mortality in acute heart failure. $\mathrm{N}$ Engl J Med 2017;376:1956-1964.

195. Moiseyev VS, Poder P, Andrejevs N, et al. Safety and efficacy of a novel calcium sensitizer, levosimendan, in patients with left ventricular failure due to an acute myocardial infarction. A randomized, placebo-controlled, double-blind study (RUSSLAN). Eur Heart J 2002;23:1422-1432. 196. Mebazaa A, Nieminen MS, Packer M, et al. Levosimendan vs dobutamine for patients with acute decompensated heart failure: the SURVIVE randomized trial. JAMA 2007;297:1883-1891.

197. Velazquez EJ, Morrow DA, DeVore AD, et al. Angiotensin-neprilysin inhibition in acute decompensated heart failure. N Engl J Med 2018 Nov 11 [Epub]. https:/doi. org/10.1056/NEJMoa1812851.

198. O'Connor CM. High heart failure readmission rates: is it the health system's fault? JACC Heart Fail 2017;5:393.

199. Gupta A, Allen LA, Bhatt DL, et al. Association of the hospital readmissions reduction program implementation with readmission and mortality outcomes in heart failure. JAMA Cardiol 2018;3:44-53.

200. Pandey A, Golwala H, Xu H, et al. Association of 30-day readmission metric for heart failure under the hospital readmissions reduction program with quality of care and outcomes. JACC Heart Fail 2016;4:935-946.

201. Wadhera RK, Joynt Maddox KE, Wang Y, Shen C, Yeh RW. 30-Day episode payments and heart failure outcomes among medicare beneficiaries. JACC Heart Fail 2018; 6:379-387.

202. Gupta A, Fonarow GC. The hospital readmissions reduction program-learning from failure of a healthcare policy. Eur J Heart Fail 2018;20:1169-1174.

203. Johnson KW, Torres Soto J, Glicksberg BS, et al. Artificial intelligence in cardiology. J Am Coll Cardiol 2018;71:26682679.

204. Ahmad T, Lund LH, Rao P, et al. Machine learning methods improve prognostication, identify clinically distinct phenotypes, and detect heterogeneity in response to therapy in a large cohort of heart failure patients. J Am Heart Assoc 2018;7:e0o8081. 